\title{
Deficit Reduction Through Diversity: How Affirmative Action at the FCC Increased Auction Competition
}

\author{
Ian Ayres* and Peter Cramton**
}

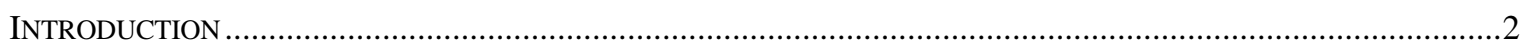

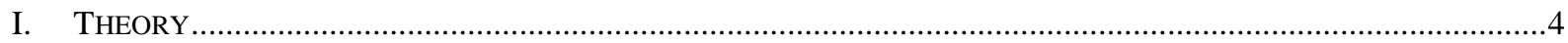

A. Set-Asides Can Enhance Intragroup Competition Among Strong Bidders........................................6

B. Bidding Credits Can Create Effective Set-Asides.............................................................................. 7

C. Bidding Credits Can Create Intergroup Competition ................................................................

D. Affirmative Action Can Increase Expected Revenue When the Government Is Imperfectly Informed

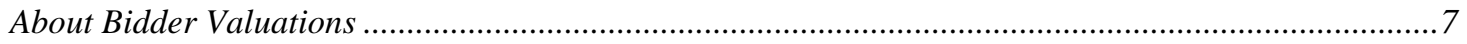

E. Affirmative Action Can Destabilize Tacit Collusion..............................................................................9

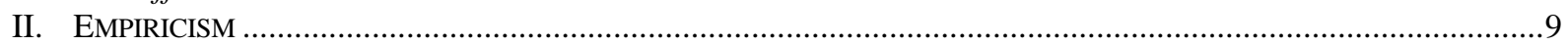

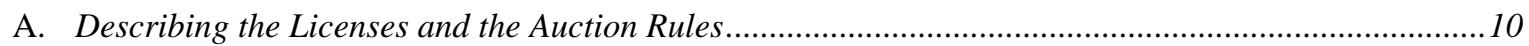

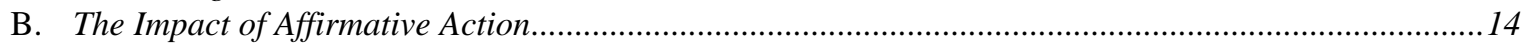

1. Comparing the nationwide and regional results................................................................. 14

2. The impact of designated crossover bidding............................................................................. 17

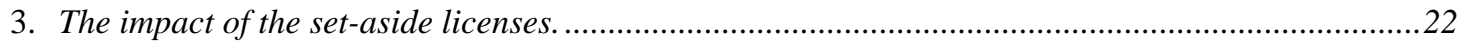

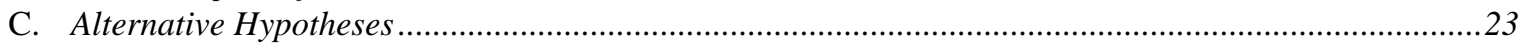

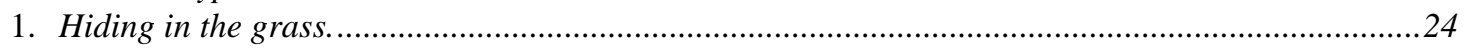

2. The designated bidders would have bid anyway ..........................................................................25

3. Affirmative action might have chilled non-designated bidder participation.....................................26

D. Strategic Perversities: Bidding Above Atomistic Reservation Prices..................................................26

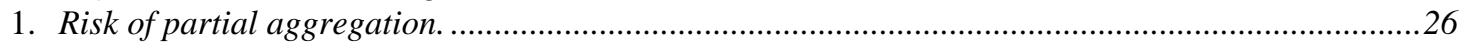

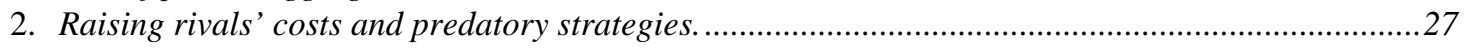

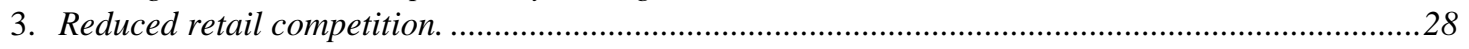

III. APPLICATIONS TO GOVERNMENT PROCUREMENT AND PRIVATE EMPLOYMENT ........................................29

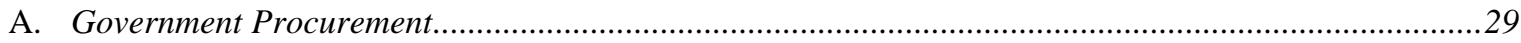

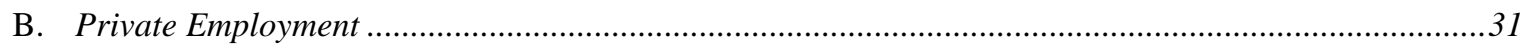

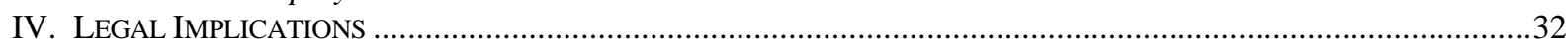

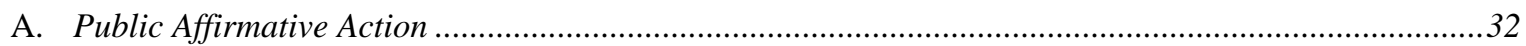

1. Revenue enhancement is constitutionally insufficient..................................................................32

2. Did the FCC's rules enhance minority or female control of the airwaves ?...................................33

3. Affirmative action costs the government less than is commonly assumed........................................34

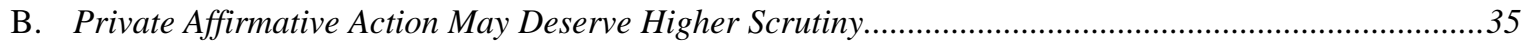

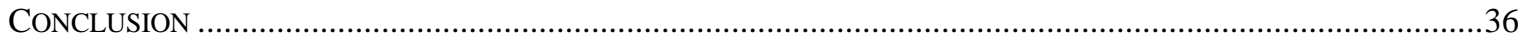

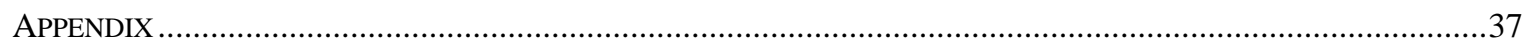

In recent auctions for paging licenses, the Federal Communications Commission has granted businesses owned by minorities and women substantial bidding credits. In this article, Professors Ayres and Cramton analyze a particular auction and argue that the affirmative action bidding preferences, by increasing competition among auction participants, increased the government's revenue by \$45 million. Subsidizing the participation of new bidders can induce established bidders to bid more aggressively. The authors conclude that this revenue-enhancing effect does not provide a sufficient constitutional justification for affirmative action-but when such justification is independently present, affirmative actions can cost the government much less than is currently thought. 


\section{INTRODUCTION}

Congress first authorized the Federal Communications Commission ("FCC") to auction licenses for slices of the radio spectrum in $1993 .{ }^{1}$ Since then, FCC auctions have raised nearly $\$ 9$ billion. ${ }^{2}$ AS part of these auctions, Congress required the FCC to "ensure that . . . businesses owned by members of minority groups and women are given the opportunity to participate in the provision of spectrum-based services, and, for such purposes, consider the use of tax certificates, bidding preferences, and other procedures." ${ }^{3}$ Relying on this statutory mandate, the FCC has at times granted substantial bidding preferences to firms controlled by women or minorities ("designated bidders").

This article focuses on the "regional narrowband" auction of thirty licenses for use in advanced paging services (which might, for example, both transmit and receive messages). ${ }^{4}$ Designated bidders in the regional narrowband auction were allowed to pay for any of the licenses in installments over ten years at a favorable interest rate ${ }^{5}$ and, on ten of the thirty narrowband licenses, were granted a 40 percent bidding credit. ${ }^{6}$ When both preferences applied, the combined effect was that favored bidders had to pay the government only 50 percent of a winning bid. ${ }^{7}$

The FCC's affirmative action has been criticized as a huge giveaway, ${ }^{8}$ but this article will show that the bidding preferences increased the government's revenue by more than 12 percent-an increase in total revenues of nearly $\$ 45$ million. Although at first blush it seems that allowing designated bidders to pay fifty cents on the dollar would necessarily reduce the government's revenue, we will show that subsidizing designated bidders created extra competition in the auctions and induced the established, unsubsidized firms to bid higher.

The unsubsidized firms bid more both because they had fewer licenses for which to compete (once the substantial designated preferences effectively set aside ten of the thirty licenses) and because they had to compete against the subsidized designated bidders crossing over to bid on non-set-aside licenses. The regional narrowband auction is a vivid example of how subsidized bids by a minority- or female-controlled firm can substantially increase the price that the government receives from a non-designated firm. Early in the auction, a non-designated firm (PageMart), attempting to aggregate a national license by bidding for all five regional licenses on a particular frequency block, had succeeded in outbidding all of its non-designated rivals by offering to pay a total of $\$ 76$ million. ${ }^{9}$ However, a minority-controlled bidder, PCS Development, entered the fray, upping the ante more than a dozen times and forcing PageMart ultimately to bid $\$ 93$ million to win the licenses. The additional competition from the minority-controlled firm increased the government's revenue by $\$ 16$ million. ${ }^{10}$ The extra revenue the government earned from unsubsidized winning bidders, such as PageMart, more than offset the subsidy to the designated bidders. Far from being a giveaway, affirmative action bidding preferences induced competition that prevented established firms from buying the airwaves at substantial discounts.

* William K. Townsend Professor of Law, Yale Law School.

** Associate Professor, Department of Economics, University of Maryland. Steve Bainbridge, Jennifer Brown, Richard Craswell, Rob Gertner, and seminar participants at the University of Arizona, the University of Chicago Law School, and the Massachusetts Institute of Technology provided helpful comments. Franklin Parlamis provided excellent research assistance.

The authors are grateful to Rob Gertner and other participants at University of Chicago Law and Economics workshops for discussions about advantages that the FCC has over private sellers.

147 U.S.C. $\$ 309(j)$ (Supp. 1995). The FCC previously awarded licenses by lottery or by comparative hearing. See text accompanying notes 172-173 infra.

${ }^{2}$ See Peter C. Cramton, The PCS Spectrum Auctions: An Early Assessment 2 (Aug. 25, 1995) (unpublished manuscript, on file with the Stanford Law Review). The auctioned frequencies were made available to personal communication services ("PCS") providers. The FCC auctioned 10 nationwide narrowband PCS licenses in July 1994, 30 regional narrowband licenses in October and November 1994, and 99 broadband licenses for Major Trading Areas ("MTAs") from December through March 1995. Id. A second broadband auction for 493 licenses was scheduled for the spring of 1995 but was delayed by litigation over the FCC's bidding preferences for small businesses, women, and minorities. The auction ultimately was rescheduled for December 18, 1995. See note 128 infra.

347 U.S.C. § 309(j)(4)(D) (Supp. 1995).

${ }^{4}$ Because of their narrow bandwidth, however, these licenses are ill-suited for cellular or other real-time voice services: Cellular services require broadband $(30 \mathrm{MHz})$ transmission, up to 600 times wider than the spectrum assigned to narrowband (50 kHz), while narrowband transmission is sufficient for delayed voice or data services. For example, downloading phone messages to a pager for later playback only requires a narrowband license. See Cramton, supra note 2, at 2.

${ }^{5}$ See notes 51-55 infra and accompanying text for a description of the installment subsidy.

${ }^{6}$ For example, due to the bidding credit, a designated bidder who won a license with a bid of $\$ 10$ million would only owe the government $\$ 6$ million. See text accompanying notes 44-50 infra for a detailed description of the specific frequency blocks to which these bidding credits applied.

${ }^{7}$ See notes 61-63 infra and accompanying text for a calculation of the combined subsidies. If a designated bidder prevailed on one of the 20 licenses to which the $40 \%$ bidding credit did not apply, the government would receive an estimated $84 \%$ of the winning bid. Id.

${ }^{8}$ See, e.g., Jonathan Rauch, Color TV. THE New RePuBLIC, Dec. 19, 1994, at 9.

${ }^{9}$ Even though no other firm raised PageMart's bids for several rounds, the simultaneous auction was designed to remain open until there were no new bids on any of the 30 licenses. See notes 45-46 infra and accompanying text. The final results of the auction appear in Table 3 infra.

${ }^{10}$ See text accompanying note 83 infra. 
Our positive thesis is that affirmative action can enhance bidding competition and thereby increase revenue. Of course, this can only occur where competition among unsubsidized bidders would otherwise fail-for example, if there were a shortage of serious unsubsidized bidders or if bidders were to collude, explicitly or tacitly. Moreover, affirmative action's capacity to enhance competition is not limited to situations where the government is a seller. Indeed, the government buys far more than it sells, and affirmative action bidding preferences may reduce the cost of government acquisitions for the same reasons. When competing against subsidized bidders for government contracts, unsubsidized suppliers may lower their bids to increase their chances of winning the new contract.

More broadly, this analysis reveals a potential profit motive for private affirmative action. Just as competition among unsubsidized bidders may not maximize the auction organizer's revenue, competition among workers in some labor markets may not maximize employer profits. If competition among the strongest job applicants is not sufficient for the employer to extract all the gains of trade from the employment relationship, then employers may have an incentive to subsidize weaker candidates, thereby inducing stronger applicants to work harder or for a lower wage. ${ }^{11}$

While we show that affirmative action at the FCC's regional narrowband auction decreased the budget deficit (and might plausibly be used to reduce government procurement costs or to increase private profits), we do not argue that this revenue-enhancing effect is normatively sufficient to justify race- or gender-conscious decisionmaking. Indeed, using affirmative action to reduce the budget deficit would not satisfy either prong of Adarand's strict scrutiny analysis: ${ }^{12}$ Raising additional revenues is not a "compelling governmental purpose," and race-conscious means are not "narrowly tailored" to further that goal-race-neutral subsidies of small bidders would also likely be able to enhance the government fisc.

The revenue-enhancing effect, however, shows that affirmative action may cost the government less than previously thought. Demonstrating that such measures need not drain the treasury might be imperative for garnering legislative support. Thus, even if the revenue effect is not constitutionally sufficient to justify affirmative action, it may establish a necessary condition for politically justifying it.

The relevance of showing that affirmative action subsidies do not burden the treasury is apparent in current debates surrounding the various California ballot initiatives to end state-sponsored affirmative action. ${ }^{13}$ Proponents of these initiatives trumpet the nonpartisan estimates of the legislative analyst office that the state could save tens of millions of dollars annually by eliminating affirmative action. ${ }^{14}$ These estimates assume that affirmative action increases the state's procurement costs whenever the state rejects a low bid to contract with historically disadvantaged firms. ${ }^{15}$ But the take-home lesson of this article is that affirmative action may not cost nearly as much as such crude estimates. In the procurement context, there is anecdotal evidence that affirmative action bidding subsidies have destabilized tacit collusion among unsubsidized bidders and have thereby reduced the average cost of procurement. The all-too-familiar story of a few government suppliers entering inflated, collusive bids can be rewritten by affirmative action initiatives that subsidize new entrants and thereby spur more competition. An unidentified source at the California Department of Transportation reports that affirmative action has forced the price of winning construction bids to approach independent estimates of construction costs. ${ }^{16}$

But in emphasizing the normative relevance of enhanced bidding competition, it is also important to recognize that increased government revenue (or decreased government cost) does not imply that affirmative action subsidies promote efficiency. Indeed, the beneficial impact on the government's revenue from bidding subsidies will often come at a cost of some economic inefficiency-in equilibrium some contracts will be awarded to lower-valuing buyers (or higher-cost producers). While enhancing market competition usually increases efficiency, enhancing bidding competition through affirmative action subsidies simply allows the government to capture more of the gains of trade, usually at the cost of some inefficiency. ${ }^{17}$ These inefficiencies,

\footnotetext{
${ }^{11}$ The troubling aspects of describing beneficiaries of affirmative action as "weaker candidates" are discussed infra at note 20. scrutiny).

${ }^{12}$ Adarand Constr. v. Pena, 115 S. Ct. 2097 (1995) (holding that federal government affirmative action measures must pass strict

${ }^{13}$ Several constitutional amendments concerning affirmative action have been filed with the California Attorney General for potential inclusion on the 1996 ballot. See, e.g., Cad Ingram, Affirmative Action Measures Threaten to Confuse Voters, L.A. TimES, July 3, 1995, at A3. Perhaps the most prominent of these is the California Civil Rights Initiative. See The Great Debate Over Affirmative Action S.F. CHRON., Jan. 19, 1995, at A21.

${ }^{14}$ William F. Buckley, California's New Fight Over Civil Rights, THE FreSNO BeE, Jan. 12, 1994, at B7.

${ }^{15}$ For example, $16 \%$ of prime contractors responding to a 1986 survey by the California Construction Industry Research Board reported submitting the lowest bid on a federal project within the previous year but losing that project because of failure to meet affirmative action goals. These contractors reported that the winning bids were on average 5.3\% higher than their own low bids. Charles Oliver, Making California Colorblind?, INVESTOR's Bus DAILY, Mar. 21, 1995, at Al, A2.

${ }^{16}$ Confidential conversation with Ayres (1995).

${ }^{17}$ To the extent that the subsidies increase revenue, the cost due to an inefficient assignment may be more than offset by the efficiency gain from raising revenues in a nondistortionary way. Governments need revenue, which is normally raised by taxation. Taxation, however, is distortionary. Economists estimate that the welfare loss from increasing taxes is in the range of 17 to 56 cents per dollar of extra
} 
however, may be short-term if affirmative action promotes new entry that stimulates subsequent, unsubsidized market competition. Moreover, there may be no efficiency loss if lower designated bids simply reflect inability to pay (possibly caused by discrimination in credit markets) rather than less prospective ability to supply paging services. $^{18}$

This paper is divided into four parts. Part I analyzes a series of game theoretic examples to show how bidding preferences could enhance government revenue. In Part II, we illustrate how this occurred in the FCC's regional narrowband auction. Part III identifies a limited set of other contexts where affirmative action might be profitable. Finally, Part IV explores the normative and legal implications of affirmative action's revenueenhancing effect.

\section{THEORY}

An auction with few bidders can generate selling prices substantially below the highest bidders' valuations. Foreclosure sales, for example, are notorious for this type of competitive failure: If only two bidders show up to bid on a single piece of property, the bidder with the higher valuation will only have to outbid her counterparteven if the lower bid is only a fraction of the property's true market value. ${ }^{19}$

Giving bidding preferences to weak bidders ${ }^{20}$ can increase auction revenues by inducing stronger bidders to bid more aggressively. Bidding preferences can enhance both "intragroup" and "intergroup" auction competition: Bidding preferences that reduce the quantity available to strong bidders may cause them to bid more aggressively among themselves (intragroup competition); subsidizing weak bidders may allow them to challenge strong bidders (intergroup competition). ${ }^{21}$

Giving bidding preferences to relatively weak bidders, however, is likely to enhance expected revenue only if: (1) there is insufficient competition among the highest valuing bidders, and (2) the seller is able to identify stable classes of bidders who are likely to have relatively low valuations. The first of these conditions is likely to hold where there are few bidders relative to the number of goods auctioned. The auction price is determined by the value of the last bidder to drop out, and the reservation price of this last bidder is likely to be lower when fewer bidders participate in an auction. Conversely, if there are a large number of relatively high-value bidders active in an auction, then competition among these bidders by itself will allow the seller to extract most of the gains from trade, obviating the need for bidding subsidies. ${ }^{22}$

revenue raised. See Charles L. Ballard, John B. Shoven \& John Whalley, General Equilibrium Computations of the Marginal Welfare Costs of Taxes in the United States, AM. ECON. REV., Mar. 1985, at 128. Hence, even if the subsidies causes substantial inefficiencies in assignments, the welfare loss may be more than offset by a reduction in distortionary taxes. Governments should care about the revenue consequences of the auction design. See Michael H. Rothkopf \& RONALD M. HARSTAD, ReCOnCILING EFFiciency ARGUMENTS IN TAXATION AND PUBLIC SECTOR RESOURCE LEASING 1 (RUTCOR Research Report No. 66-90, 1990).

${ }^{18}$ A final normative implication of using affirmative action to enhance competition concerns the legality of affirmative action by private employers under Title VII. That some private employers may institute affirmative action programs solely to increase profits may cause courts to scrutinize private affirmative action more closely, in order to distinguish plans that seek to remedy past discrimination from those motivated solely by a desire to increase profits. See notes 165-168 infra and accompanying text.

${ }^{19}$ Similarly, in bankruptcy, secured creditors are interested in generating enough income to cover their debt, rather than in maximizing the debtor's residual value. In liquidating or reorganizing debtors, creditors have no incentive to sell corporate assets for more than the value of their claims. See Philippe Aghion, Oliver Hart \& John Moore, The Economics of Bankruptcy Reform, 8 J.L. ECON. \& ORG. 523, 525-28 (1992) (discussing obstacles to attainment of full market value for assets auctioned pursuant to a bankruptcy proceeding).

${ }^{20}$ A "weak" bidder is a bidder who has a lower expected reservation price. The highest amount that a bidder is willing or able to pay is that bidder's 'reservation price.' See Jennifer Gerarda Brown \& Ian Ayres, Economic Rationales for Mediation, 80 VA. L. REV. 323,331 n.26 (1994). In this article, we assume that a bidder knows its own reservation price, but that sellers and other bidders are imperfectly informed and can only form expectations of the bidder's reservation price.

In the regional narrowband auction, affirmative action subsidies were premised on the FCC's belief that firms controlled by women and minorities had a lower ability to pay for licenses, in part because of discrimination in credit markets. Implementation of Section 309(j) of the Communications Act-Competitive Bidding, 9 F.C.C.R. 2941, 2968-71 (1994) (Third Report and Order, PP Docket No. 93-253) [hereinafter Third Report \& Order].

Our description of designated firms as relatively weak bidders is intended only to connote that these bidders may have lower expected reservation prices. Making this assumption without sufficient empirical support risks a disabling type of stereotype. As Justice Clarence Thomas recently wrote: "It never ceases to amaze me that the courts are so willing to assume that anything that is predominantly black must be inferior." Missouri v. Jenkins, 115 S. Ct. 2038, 2061 (1995) (Thomas, J., concurring). However, the FCC's difficulties in promoting diverse participation and the results of the narrowband auction themselves support the inference that designated bidders had lower reservation prices. See Table 3 infra.

${ }^{21}$ By granting designated bidders a 50\% subsidy on two frequency blocks, the FCC effectively excluded non-designated bids, thereby forcing non-designated bidders to bid more aggressively on the remaining blocks (intragroup competition). See notes 49-50 infra and accompanying text. In addition, the FCC fostered intergroup competition by giving designated bidders a $16 \%$ subsidy on the four other frequency blocks. Id.

${ }^{22}$ R. Preston McAfee \& John McMillan, Auctions and Bidding, 25 J. ECON. LiterATURE 699, 703 (1987). Formally, if the valuations for a group of high valuers is drawn from the same probability distribution, then the expected auction price will asymptote to the highest bidder valuation as the size of the group becomes arbitrarily large. $I d$. at 711 . 
But even having as many as four excess bidders may not be sufficient to extract all of the gains of trade. For example, assume that four widgets are being auctioned to a group of bidders who have reservation prices uniformly distributed between $\$ 0$ and $\$ 100$ (and that the seller's reservation price is $\$ 0$ ). The percentage of the gains of trade that the seller captures crucially depends on the number of bidders in excess of the number of items being sold. As shown in Table 1, even with eight bidders the seller will only capture 61.5 percent of the expected gains from trade. Our analysis shows that subsidizing weak bidders can increase the seller's yield by inducing the highest valuers to bid more.

TAble 1. EFFect OF EXCESs Bidders on SELler's EXPECTEd Profits ${ }^{23}$

\begin{tabular}{cc}
\hline Number of Bidders & $\begin{array}{c}\text { Expected Percentage of Gains } \\
\text { From Trade Accruing to Seller }\end{array}$ \\
\hline 1 & 0.0 \\
2 & 0.0 \\
3 & 0.0 \\
4 & 0.0 \\
5 & 28.6 \\
6 & 44.4 \\
7 & 54.5 \\
8 & 61.5 \\
9 & 66.7 \\
\hline
\end{tabular}

The second condition for profitably subsidizing weak bidders does not require that sellers know either the bidders' reservation prices or their expected reservation prices. But sellers must be able to estimate the expected difference between the reservation prices of at least two stable groups of bidders in order to identify the weaker group and to calculate the size of the subsidy that might enhance revenue. ${ }^{24}$ Sellers would want to distinguish between expected high and low value bidders because subsidizing high-value bidders would normally reduce the expected auction revenues. ${ }^{25}$

The narrowband PCS auctions likely satisfied both conditions: an insufficient number of higher value bidders and a readily identifiable class of weak bidders. Because the demand for, and the supply of, these advanced paging services are unproven, capital markets shied away from financing companies that did not already have significant prior industry experience. This capital market constraint by itself could explain why competition among nonpreferred firms would be insufficient to drive bidding toward the highest bidders' reservation prices.

${ }^{23}$ Because the seller's reservation price is $\$ 0$, the expected gain from trade is simply the expected high value among a certain number of bidders. Statisticians call this value the first-order statistic. The expected price in an auction of four items is the fifth-order statistic. To derive Table 1, we simply calculated the first- through fifth-order statistics for different numbers of bidders (which are well-defined for the uniform distribution); we then divided the fifth-order statistic by the sum of the first- through fourth-order statistics and multiplied the result by the number of items being auctioned, which yielded the expected percentage of gains from trade accruing to the seller (as auction revenue). For example, with $n=9$ bidders, the expected value of the first- to fifth-order statistics are $0.9,0.8,0.7,0.6$, and 0.5 . Revenue is equal to $4 \mathrm{x}(0.5)=2$ and the expected gains from trade are $0.9+0.8+0.7+0.6=3$, so the seller's share is $2 / 3=66.7 \%$. For a technical discussion of expected bids, see Jeremy Bulow \& John Roberts, The Simple Economics of Optimal Auctions, 97 J. POL. EECON. 1060, 108689 (1989).

${ }^{24}$ Game-theorists use the term "private valuation" auction to refer to auctions in which each bidder knows her private valuation, but the seller and the other bidders know only the probability distribution from which this valuation is drawn. Private valuation models are usually contrasted with "common valuation" models, in which all bidders have a single, common value for the good being auctioned, but have imperfect information about what this value will turn out to be. See Peter Cramton \& Alan Schwartz, Using Auction Theory to Inform Takeover Regulation, 7 J.L. ECON. \& ORG. 27, $28-29$ (1991) (distinguishing between common value and independent private value auctions). While the narrowband auctions certainly have some aspects of a common valuation game, bidders' idiosyncratic entrepreneurial abilities inject a private valuation component which can give rise to a revenue-enhancing effect—-that is, bidders "derive different surplus from winning." Id. at 29 n.4.

${ }^{25}$ Giving bidding subsidies to a bidder who is likely to have a high valuation would reduce auction competition and lead to lower expected revenues because such a subsidy would entrench the strong/subsidized bidder and reduce the amount that this bidder would likely have to pay to win the auction.

If the seller believes that bidders' demand for multiple items to be auctioned is sufficiently inelastic, then the seller may want to set aside one or more of the items even if she cannot distinguish between higher- and lower-valuing bidders. Indeed, increased revenue from quantity reduction on the auctions without set-asides might be greater than the reduced revenue that the seller would expect to receive from the set-aside license. Where the seller cannot identify relatively weak bidders-from the seller's perspective all bidders are symmetric ex ante-arbitrary preferences will not maximize expected revenue. Under these conditions, the revenue-maximizing multi-object auction is symmetric. See generally Eric Maskin \& John Riley, Optimal Multi-unit Auctions, in THE ECONOMICS OF Missing MARKET, INFORMATION, AND GAMES 312 (Frank Hahn ea., 1989). 
Since designated bidders are disproportionally underrepresented in communications technology markets, the government could reasonably expect that these capital market constraints would bind designated bidders all the more. Thus, the FCC could reasonably conclude that designated bidders would have lower reservation prices. Nonetheless, the government's informational problem was far from trivial: While the government could reasonably expect that designated bidders would be weaker, it is not clear that they knew how much weaker. And knowing the magnitude of the difference in reservation prices between strong and weak bidders is critical to calculating the size of the subsidy necessary to increase expected revenue.

To underscore how difficult it is to meet these two conditions, the reader should keep in mind that few real world sellers find it worthwhile to subsidize weak bidders to increase their expected revenue. ${ }^{26}$ For example, one would think in the context of art auctions that subsidizing museums (which are often thought to have constrained budgets) might be a way to induce private collectors to bid more. But auction houses normally do not subsidize weak bidders. The FCC, however, has several advantages over private sellers. ${ }^{27}$ Most importantly, the FCC can prohibit subsidized bidders from reselling to unsubsidized firms ${ }^{28}$ The resale possibility greatly exacerbates the private seller's informational problem: It is much more difficult to identify a class of weak bidders because a weak bidder may in effect just be purchasing on behalf of the stronger, unsubsidized bidders. By prohibiting (or I.Drestricting) resale of the designated bidders' licenses to non-designated firms, the government by fiat can eliminate the unraveling effects of resales. The FCC's decision to sell more licenses than a profit-maximizing monopolist also increased the chance that affirmative action would raise revenue: If the FCC were only interested in maximizing the auction revenue, it would have only auctioned one license per region because firms bidding for the right to have a monopoly would pay much more than firms bidding for the right to compete with many other firms. While there may have been enough established firms to create a competitive auction for single licenses, the FCC's decision to sell six narrowband licenses in each of the five regions, in addition to the ten nationwide, created the need to bring more bidders to the table to enhance auction competition.

To illustrate how affirmative action can enhance bidding competition, we begin with a series of examples showing how a particular set-aside or bidding credit increases expected revenue, without addressing whether the seller has adequate information to choose the right subsidy. In Part I.D we will then explain how an imperfectly informed seller could calculate revenue-enhancing subsidies.

In the initial series of examples, we assume that four firms are bidding to purchase two licenses and that each bidder is only interested in purchasing a single license. ${ }^{29}$ The four bidders have different reservation prices: The two strong bidders (Strong 1 and Strong $_{2}$ ) are willing to bid up to $\$ 110$ and $\$ 90$ respectively, and the two weak bidders ( $\mathrm{Weak}_{1}$ and $\mathrm{Weak}_{2}$ ) are willing to bid up to $\$ 60$ and $\$ 40$ respectively.

Using a traditional English (or open ascending) auction, in which the price rises until a single buyer remains, the government should expect to earn slightly more than $\$ 120$. The two strong bidders only need to slightly outbid the $\$ 60$ weak bidder in order to win licenses. Even though the strong bidders would have been willing, if needed, to bid more, they have no reason to compete against each other; the supply of licenses at this price is sufficient to satisfy their own demand. Using this auction as a benchmark, we will now consider a series of examples in which bidding credits and set-asides generate more than $\$ 120$ in government revenue by inducing the strong bidders to bid more aggressively.

\section{A. Set-Asides Can Enhance Intragroup Competition Among Strong Bidders}

Sellers can induce more competition among strong bidders, and therefore increase auction revenues, by reducing the number of items available to the strong bidders. The quantity available for strong bidders can be reduced simply by setting aside one of the licenses to be auctioned only among the weak bidders. The set-aside license will be auctioned for just over $\$ 40$ as $W_{e a k}$ will bid slightly more than Weak ${ }_{2}$ 's reservation price. After the set-aside, there are no longer enough licenses to satisfy strong-bidder demand, and these bidders accordingly will bid more aggressively for the remaining license. This remaining license will be auctioned for slightly more than $\$ 90$ as Strong 1 will bid slightly more than Strong,'s reservation price-and $\$ 30$ more than it would bid

\footnotetext{
${ }^{26}$ Sellers often do establish minimum auction bids (often referred to as the "reserve price", above their own value, which has the effect of subsidizing themselves as a particular type of weak bidder. See note 35 infra and accompanying text (discussing effect of seller reserve prices). We revisit this informational problem when we assess the analogous use of affirmative action by private employers. See notes 142-147 infra and accompanying text.

${ }^{27}$ The Robinson-Patman Act's (rarely enforced) prohibition against price discrimination may deter sellers from subsidizing weak bidders - especially as here when bidders subsequently compete with each other. Robinson-Patman Act, 15 U.S.C. § 13a (1994).

${ }^{28}$ The FCC rules do not specifically address the leasing of licenses from a designated bidder to a non-designated bidder. See Third Report and Order, supra note 20, at $\mathbf{9}$ 66-89. This failure may increase the possibility of a sham designated bidder. However, if the lease was structured in a way that the designated bidder effectively lost control of the license, then presumably the FCC would prohibit the arrangement, since it would amount to a change in control.

${ }^{29}$ We assume that a single license will give the bidder sufficient capacity to serve al] of the demand in me geographic area. Alternatively, we might have assumed that the FCC prohibits any firm from owning more than one license in a geographic area.
} 
absent the set-aside. Setting aside one license thus raises the government's expected revenue to slightly more than $\$ 130$, an increase of $\$ 10$. Despite increasing government revenue, the set-aside also reduces efficiency-one of the licenses ends up in the hands of a $\$ 60$ valuer instead of a $\$ 90$ valuer. $^{30}$

\section{B. Bidding Credits Can Create Effective Set-Asides}

Like explicit set-asides, bidding credits can enhance government revenues by effectively reducing the quantity available to strong bidders. Consider a bidding credit that allows weak bidders to pay only 50 percent of their winning bids. Because of this 50 percent bidding credit, Weak, would be willing to bid up to $\$ 120$. Therefore, Strong, and Weak, would each win a license by bidding slightly more than $\$ 90$ (Strong2's reservation price). ${ }^{31}$ The government revenue from this auction would be approximately $\$ 135$ : Strong ${ }_{1}$ would pay slightly more than $\$ 90$ and Weak, would pay 50 percent of its bid, or slightly more than $\$ 45$. The bidding credit reduces the quantity available to the strong bidders. Because neither strong bidder will bid up to Weak ${ }_{1}$ 's $\$ 120$ subsidized reservation price, they will compete with each other for one license, driving its price to $\$ 90$. The bidding credit

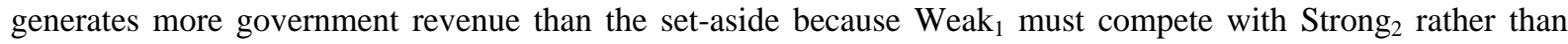
$\mathrm{Weak}_{2}$ to win a license. Like the set-aside, the 50 percent bidding credit induces inefficiency by allowing Weak, to win a license instead of Strong 2 ; nonetheless, the government realizes more revenue than it would either with a traditional English auction or with a set-aside.

\section{Bidding Credits Can Create Intergroup Competition}

Properly calibrated bidding credits can simultaneously cause strong bidders to bid more aggressively and avoid inefficiency. With a 25 percent credit (rather than the previous 50 percent), Weak $k_{1}$ will bid $\$ 80,{ }^{32}$ and the strong bidders will each win a license by bidding slightly more than this amount. The total auction revenue will be slightly more than $\$ 160$. The 25 percent bidding credit induces intergroup competition as weak bidders raise the amounts that strong bidders must pay to win licenses. Absent any bidding preference, the strong bidders pay only $\$ 60$ per license, but the bidding credit forces each strong bidder to increase its bid $\$ 20{ }^{33}$

\section{Affirmative Action Can Increase Expected Revenue When the Government Is Imperfectly Informed About Bidder Valuations}

The foregoing examples make clear that bidding preferences can enhance government revenues when the seller knows the reservation prices of the individual bidders. Imputing this knowledge to sellers, however, is unreasonable, not only because they seldom have this information, but also because if they did, knowledgeable sellers would maximize revenue by setting firm-specific reservation prices. For example, if the government knew the reservation prices of the strong firms, it would simply make Strong ${ }_{1}$ and Strong 2 take-it-or-leaveit offers of slightly less than $\$ 110$ and $\$ 90$ respectively.

In this section, we show how bidding preferences can enhance revenue even when sellers are imperfectly informed about bidder valuations. When sellers do not know bidders' exact valuations, subsidizing weak bidders may allow a low-value bidder to buy a license for a low price, resulting in reduced revenue and lost efficiency. Nonetheless, the expected benefits of more aggressive bidding by strong bidders may outweigh this cost:

There is a trade-off. By favoring the low-valuation type of bidders, the seller raises the probability of awarding the item to someone other than the bidder who values it the most and receiving a relatively low payment. The benefit from this policy, however, is that the favoritism forces the bidders from the high valuation class to bid higher than they otherwise would, driving up the price on average. ${ }^{34}$

The intuition behind this result explains why sellers in an auction sometimes set a reserve price above their actual valuations. With an inflated reserve price, the sellers are in effect subsidizing themselves as bidders. Although an inflated reservation price can induce more aggressive bidding by unsubsidized bidders, sellers also increase the risk that they will sell the item back to themselves. ${ }^{35}$

\footnotetext{
${ }^{30}$ The set-aside correspondingly reduces the profits or, in game-theoretic terms, payoffs that the strong bidders would earn in the absence of a set-aside. The set-aside reduces the payoffs to the strong bidders by $\$ 60$. Strong1,s payoff decreases from $\$ 50$ to $\$ 20$ : Without the set-aside. Strong1 pays $\$ 60$ for a license it values at $\$ 110(\$ 110-\$ 60=\$ 50)$ whereas with the set-aside Strong 1 must pay $\$ 90(\$ 110-$ $\$ 90=\$ 20)$

${ }^{31}$ Weak $_{2}$ would not bid more than $\$ 80$, because winning at more than this price would force it to pay more than its reservation price of $\$ 40$.

${ }^{32}$ Bidding more than $\$ 80$ would force Weak ${ }_{1}$ to pay more than its $\$ 60$ reservation price if it won a license $(\$ 80 \times(1-0.25)=\$ 60)$.

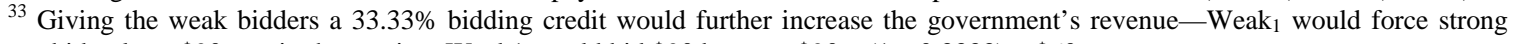
bidders to bid at least $\$ 90$ to win the auction. Weak1 would bid $\$ 90$ because $\$ 90 \times(1-0.3333)=\$ 60$.

${ }_{35}^{34}$ McAfee \& McMillan, supra note 22, at 715.

${ }^{35} \mathrm{Id}$ at $715 \mathrm{n} .19$ ("The optimal reserve-price policy . . . can . . . be seen to be a special instance of this optimal discriminatory policy, with the seller discriminating between himself, as an implicit bidder, and the actual bidders."); see also Robert C. Marshall, Michael J. Meurer \& Jean-Fraņois Richard, The Private Attorney General Meets Public Contract Law: Procurement Oversight By Protest, 20
} 
To see the effect of affirmative action in a specific imperfect information example, consider a seller auctioning a single good between two potential risk-neutral buyers. ${ }^{36}$ Assume that the reservation price for the first potential buyer (Strong) is drawn from a uniform probability distribution that is equally likely to take on any value between $\$ 100$ and $\$ 300$ million, and that the reservation price for the second potential buyer (Weak) is drawn from a distribution that is equally likely to take on any value between $\$ 0$ and $\$ 100$ million. Also assume that the seller's reservation price is known to be $\$ 0$.

With only these two bidders in a traditional English auction with open ascending bids, Strong will always win, paying an expected price of $\$ 50$ million (the price where on average Weak would stop bidding). In this simple auction, the weak bidder offers little competition to the strong one. As suggested above, the seller can encourage more aggressive bidding by entering a bid above its own $\$ 0$ valuation: Setting a reserve price of $\$ 150$ million increases the seller's expected revenue from $\$ 50$ million to $\$ 112.5$ million. $^{37}$

A revenue-maximizing seller can still do better. The seller can induce even more bidding competition by subsidizing both itself and the weak bidder. As originally derived by Myerson, ${ }^{38}$ the optimal English auction should take the following form:

The seller should set a $\$ 150$ million reserve price, i.e. the minimum acceptablebid, and give Weak a $\$ 100$ million bidding credit. ${ }^{39}$

With the bidding credit, Weak competes more vigorously with Strong because, for example, if Weak's value was $\$ 60$ million, it would be willing to bid up to $\$ 160$ million. Even though it is common knowledge that Weak's valuation is lower than Strong's valuation, the seller can use Weak to extract higher bids from Strong. In this revenue-maximizing auction, the seller's expected revenue rises to $\$ 120.83$ million; the bidding preference for the weak bidder raises the expected revenue by more than $\$ 8.3$ million. ${ }^{40}$

These enhanced expected revenues come at the expense of efficiency: As before, subsidizing weaker bidders creates the possibility that lower valuing owners will purchase the good. For example, if Weak's value is $\$ 80$

HOFSTRA L. REV. 1, 8 (1991) ("The . . reserve . . force[s] vendors to bid more aggressively to ensure that they exceed the reserve. When a reserve has been optimally set, the potential ex post inefficiency from making no award is more than offset, in an expected sense, by the higher surplus generated from more aggressive bidding.").

${ }^{36}$ This example is adapted from one found in Bulow \& Roberts, supra note 23, at 1061. Uniform distribution examples also can be found in Roger B. Myerson, Optimal Auction Design, 6 MATH. OPERATIONS Res. 58, 59 (1981).

${ }^{37}$ Three-quarters of the time, Strong will bid $\$ 150$ million, the other quarter of the time, Strong will bid between $\$ 100$ and $\$ 150$ million, and the seller will retain the good $((\$ 150 \times 0.75)+(\$ 0 \times 0.25)=\$ 112.5)$. Setting a reserve pace of $\$ 100$ million would increase the seller's expected revenue from $\$ 50$ to $\$ 100$ million, because, under our assumptions, Strong will always be willing to bid at least $\$ 100$ million. But our example shows that setting a reserve price above both the seller's and Strong's minimum value can be a revenue maximizing strategy. See Bulow \& Roberts, supra note 23, at 1064-69.

${ }^{38}$ See Myerson, supra note 36. Myerson employed mechanism design techniques to derive the optimal auction design. He assumes there are $n$ bidders and a single good being sold. (The analysis applies to multiple goods, so long as their values are not interdependent.). Bidder $i$ 's valuation $v_{i}$ is known only to $i$, but it is commonly known among bidders that each $v$; is drawn independency from the distribution $F_{j}$ with density $f_{i}$.

In the symmetric case, where each valuation is drawn from the same distribution $\left(F_{i}=F_{j}=F\right)$, the seller optimally treats the bidders the same, and the good goes to the bidder with the highest valuation $v_{i}$. Moreover, any of the standard auction forms (with the optimal reserve) maximizes revenue for the seller. Myerson shows that the seller optimally awards the good to the bidder with the highest value of $J\left(v_{i}\right)=v_{i}-\left[1-F\left(v_{i}\right)\right] / f\left(v_{i}\right)$ (assuming $J$ is increasing in $v_{i}$; and $J$ is positive for the bidder with the highest valuation $v_{i}$ ). See Id. at 66. The second term, $\left[1-F\left(v_{i}\right)\right] / f\left(v_{i}\right)$, represents the information rent going to the winning bidder. This is equal to the expected difference between the highest and second highest valuation.

In the asymmetric case, $\left(F_{i} \pi F_{j}\right)$, the seller optimally treats bidders differently. In this case, the seller does not always award the good to the bidder with the highest valuation $v_{i}$. Rather, the seller manipulates bidders' incentives to increase competition among the bidders at the auction. More precisely, the seller optimally awards the good to the bidder with the highest value of $J_{i}\left(v_{i}\right)=v_{i}-\left[1-F\left(v_{i}\right)\right] / f\left(v_{i}\right)$.

For example, if bidder $i$ 's valuation is uniformly distributed between $a_{i}$ end $b_{i}$, then $F_{i}\left(v_{i}\right)=\left(v_{i}-a_{i}\right) /\left(b_{i}-a_{i}\right), f_{i}\left(v_{i}\right)=1 /\left(b_{i}-a_{i}\right)$, and $J_{i}\left(v_{i}\right)=2 v_{i}-b_{i}$. See Bulow \& Roberts, supra note 23, at 1067. Suppose there are two bidders, Weak and Strong. Weak's maximum valuation, $b_{w}$, is less than Strong's maximum valuation, $b_{s}$ According to the rule above, the seller awards the good to Weak if $2 v_{w}-b_{w}>2 v_{s}$ $-b_{s}$, or $v_{w}>\mathrm{v}_{\mathrm{s}}-\left(b_{s}-b_{w}\right) / 2$. Since $b_{s}>b_{w}$, Weak is favored in the optimal auction because Weak will sometimes win even when Strong values the good more than Weak. In an ascending-bid auction, the seller implements this preference by giving similarly situated weak bidders a bidding credit of $\left(b_{s}-b_{w}\right) / 2$.

${ }^{39}$ For explanation of this form of auction, see Bulow \& Roberts, supra note 23 at 1069-77.

${ }^{40}$ In equilibrium, the payoffs for Strong and Weak average $\$ 47.92$ million and $\$ 4.17$ million, respectively. The bidding preference, however, induces inefficiency, because the weaker bidder wins the auction 3/16th of the time (and because the reserve pace prevents trade $1 / 8$ th of the time) Without the bidding preference or the reserve pace, Strong always wins and produces average "gains of trade" equaling $\$ 200$ million. Without the bidding preference but with the $\$ 150$ million reserve pace, the seller inefficiently retains the good $25 \%$ of the time - the total gains of trade therefore fall to $\$ 168.75$ million $((300+150) /(2 \times 0.75)+(0 \times 0.25))$. With both the $\$ 100$ million bidding preference and the $\$ 150$ million reserve pace, the average "gains of trade" are $\$ 172.92$ million (gain from optimal auction $=120.83+4.17+$ $47.92=\$ 172.92)$-which represents $13.54 \%$ inefficiency; the gain from an English auction would be $\$ 200(50+0+150)$. See Bulow \& Roberts, supra note 23, at 1064-69 (discussing construction of an optimal auction). Bidding credits improve efficiency, holding the $\$ 150$ million reserve pace constant, because the auction without the bidding credit completely ignores Weak and instead promotes competition by subsidizing an even weaker bidder (the seller). The bidding credit allows the seller to use Weak to induce Strong to pay more. Trade occurs $7 / 8$ th of the time with the bidding credit, rather than just $6 / 8$ th of the time with the optimal reserve pace alone. 
million and Strong's value is $\$ 170$ million, then Weak would win the auction with a bid slightly above $\$ 170$ million (and would pay only slightly above $\$ 70$ million).

In general, the size of the bidding that will maximize revenue depends on the seller's beliefs about the strong and weak bidders' relative valuations. ${ }^{41}$ But this example has shown that a seller cannot do as well by merely establishing minimum acceptable bids. When a seller has imperfect information about the buyers' values, subsidizing weak bidders may be necessary to maximize the seller's expected returns.

\section{E. Affirmative Action Can Destabilize Tacit Collusion}

Fostering additional competition by subsidizing weaker bidders may also destabilize incentives for bidders to collude tacitly. The incentives for tacit collusion are particularly acute where multiple products are being auctioned: Rational bidders consider how bidding on one product may affect the price that they will pay on other products—and might accordingly bid less.

To see how tacit collusion occurs, imagine that Sprint and AT\&T are competing for two licenses: one in Philadelphia and the other in Boston. To keep things simple, assume that it is commonly known that AT\&T has a reservation price of $\$ 10$ million for each license and that Sprint's reservation prices for the Philadelphia and Boston licenses are $\$ 8$ and $\$ 7$ million respectively. Also assume that without affirmative action, no other bidder would bid more than $\$ 2$ million for either license.

How much money should the government expect to make from the simultaneous auctioning of these two licenses? If both AT\&T and Sprint ignore the impact of their bidding on the other license's price, then the government should earn slightly more than $\$ 15$ million—as AT \& T would outbid Sprint to win both licenses.

Rational bidders, however, will consider how bidding on one license may affect the other license's price. Specifically, AT\& T may decide to bid only slightly above $\$ 2$ million for the Boston license and to refrain from bidding for the Philadelphia license. AT\&T'S strategy would be an implicit offer to Sprint to divide the markets: "We'll let you buy the Philadelphia license cheaply, if you let us buy the Boston license cheaply." Coupled with this implicit invitation comes an implicit threat: If Sprint bids to increase the price of the Boston license, AT\&T will retaliate by bidding up the Philadelphia license's price. ${ }^{42}$

If Sprint accepts this implicit offer, AT\&T and Sprint will each purchase a license for slightly more than \$2 million. Both parties have an incentive to abide by this market-division agreement, because they earn higher profits by coordinating their bidding behavior rather than by competing. AT\&T does better by buying one license for a low price than by buying two licenses for relatively high prices. Without the tacit market division, AT\&T's expected profit would be $\$ 5$ million (because it would pay $\$ 15$ million for licenses that it valued at $\$ 20$ million). Dividing the market, however, increases AT\&T's payoff to $\$ 8$ million (because it buys a $\$ 10$ million license for only $\$ 2$ million). ${ }^{43}$

Affirmative action can destabilize this collusive equilibrium. If the government gave weak bidders a 67 percent bidding credit, weak bidders (with $\$ 2$ million reservation prices) would be willing to bid up to approximately $\$ 6$ million. Facing subsidized competitors, AT\&T would no longer want to divide the market. Tacit collusion would now allow AT\&T to realize only a $\$ 4$ million payoff on the Boston license, while AT\&T would earn $\$ 5$ million by bidding aggressively on both licenses (buying one $\$ 10$ million license for $\$ 8$ million and the other for $\$ 7$ million).

The moral of these reductive economic fables is quite simple: Subsidizing weak bidders can enhance a seller's auction revenue by forcing strong bidders to bid more aggressively. Bidding subsidies for weak biddersfar from being "giveaways" - can prevent giveaways by forcing relatively strong bidders to bid closer to their reservation prices. Nonetheless, the subsidies often cause inefficiency whenever the good is actually sold to a weak bidder. But this is a cost that revenue-maximizing sellers are willing to bear. Such sellers might consider the windfall that occasionally accrues to a weak bidder as a fee for enhancing the auction competition.

\section{EMPIRICISM}

${ }^{41}$ Whenever the valuation distributions have the same shape but different means, sellers seeking to maximize expected auction revenue will subsidize bidders with the lower mean. See McAfee \& McMillan, supra note 22, at 715.

${ }^{42}$ Sprint, rather than AT\&T, might just as easily have made the tacit "offer' to collude by initially refraining from bidding on the Boston license. Tacit "offers" and "acceptances" were especially easy to implement in the regional narrowband auction because the licenses for different regions were auctioned simultaneously, allowing any colluder to monitor its counterparty's compliance with the "agreement." Collusive behavior is more difficult to coordinate during sequential auctioning of individual licenses, because there is a stronger incentive for the early auction winner to breach the agreement and to bid in the subsequent auctions.

${ }^{43}$ The market division also clearly helps Sprint because it would win neither license without the tacit restraint but earns $\$ 6$ million by cooperating with AT\&T (as it pays $\$ 2$ million for a license that it values at $\$ 8$ million). Tacit collusion therefore reduces the government's revenue by $\$ 11$ million (from $\$ 15$ to $\$ 4$ million) and creates inefficiency by allowing Sprint to win the Philadelphia license even though its valuation of that license is lower than AT\&T's. 


\section{A. Describing the Licenses and the Auction Rules}

The FCC offered thirty licenses for sale in the regional narrowband auction: Six narrowbands of the radio spectrum (Frequency Blocks 1 through 6) were offered in each of five regions (Northeast, South, Midwest, Central, and West). Thus, each of the thirty licenses authorized transmission on a particular frequency block in a particular region.

Each frequency block was divided so that licensee pagers could both send and receive information. Two of the six licenses in every region (Blocks 1 and 2) were allocated $50 \mathrm{kHz}$ for both incoming and outgoing messages ("50/50 blocks"), while the remaining four licenses (Blocks 3, 4, 5, and 6) were allocated $50 \mathrm{kHz}$ for incoming transmissions and $12.5 \mathrm{kHz}$ for outgoing transmissions ("50/12 blocks"). ${ }^{44}$

The thirty licenses were sold in a simultaneous multiple-round auction, which is similar to a traditional English auction except that, rather than selling each license in sequence, a group of licenses is auctioned simultaneously. ${ }^{45}$ In any round a bidder may bid on any of the licenses being offered, and the auction does not close until bidding has ceased on all licenses - that is, until a round goes by in which no one raises the prevailing bid on any license. ${ }^{46}$

The FCC changed the rules governing designated subsidies just before the regional auction. In the July 1994 auction for nationwide licenses, the FCC had granted designated bidders 25 percent bidding credits on three of the ten narrowband licenses. ${ }^{47}$ The 25 percent credit, however, proved to be insufficient to allow any designated bidders to win a license- and most designated bidders dropped out after the first round of bidding. ${ }^{48}$ The FCC responded by increasing the bidding credit in the regional narrowband auction from 25 percent to 40 percent. ${ }^{49}$ The bidding credits could be used on ten of the thirty regional licenses: the five Frequency Block 2 licenses (a 50/50 block) and the five Frequency Block 6 licenses (a SO/12 block). Although the ten licenses subject to the designated bidding credit were not de jure set aside for designated bidders, the credit was large enough to create de facto set-asides. ${ }^{50}$ Thus, we will refer to these ten licenses on Blocks 2 and 6 as "effectively set-aside" or simply "set-aside."

The FCC also allowed any designated bidder that qualified as a small business to pay for its license over ten years at an attractive interest rate. ${ }^{51}$ The FCC required non-designated bidders to pay 20 percent of their winning bids within five business days of the auction's close, and the remaining 80 percent within five business days of

${ }^{44}$ Licenses of the same bandwidth that cover the same region should be perfect demand substitutes, with two qualifications. First, owning incenses with adjacent bandwidths within a particular region may be particularly valuable because a small guard band that prevents interference between adjacent licenses can be used for transmission by a single owner to increase its effective capacity. Peter C. Cramton, Money Out of Thin Air, 4 J. ECON. \& MGMT. STRAT. 267, 275 (1995). Second, owning licenses in adjacent regions on the same frequency may allow a company to reduce disruption along the geographic border of the two regions. Id.

${ }^{45}$ Some core aspects of the auction form were proposed by auction experts Paul Milgrom and Robert Wilson of Stanford University and Preston McAfee at the University of Texas. John McMillan, Selling Spectrum Rights, J. ECON. PerSPECTIVES, Summer 1994, at 145, 154. The simultaneous, open ascending bid format allowed bidders to switch among incenses. With sequential auctions, bidders must predict future prices when determining current bids. $I d$. at 153-54. The FCC's choice of the simultaneous, open ascending bid format is an extraordinary example of reliance on economic theory in the absence of empirical data. And the FCC's willingness to innovate probably increased government revenue by millions of dollars. See Cramton, supra note 2, at 35.

${ }^{46}$ Paul Milgrom, Auction Theory for Privatization (forthcoming 1996) (manuscript at 19, on file with the Stanford Law Review). To ensure that the auction would end within a reasonable time, the FCC imposed several ancillary rules, including minimum bid increments and an activity rule, which reduced a bidder's eligibility to bid in later rounds if it were inactive in early rounds. For details about the auction rules, see Implementation of Section 309(j) of the Communications Act-Competitive Bidding, 9 F.C.C.R. 5532, $5541-53$ (1994) (Fifth Report and Order, PP Docket No. 93-253) [hereinafter Fifth Report \& Order].

47 Third Report \& Order, supra note 20, at 2968.

${ }^{48}$ Results of the nationwide narrowband auction are located on the Internet at http: //www.fcc.gov/ pub/ Auctions/ PCS/ Narrowband/ Nationwide/finalbid.txt. Although bidder identities were supposed to be confidential, most designated bidders physically left the auction site early in the bidding. Because it was relatively easy for big, established bidders to identify each other, the FCC made bidder identities public for the second auction.

${ }^{49}$ Implementation of Section 309(j) of the Communications Act-Competitive Bidding Narrowband PCS, 10 F.C.C.R. 175, 201 (1994) (Third Memorandum Opinion and Order and Further Notice of Proposed Rulemaking, PP Docket No. 93-253) [hereinafter Third Memorandum \& Order]. The FCC also expanded the definition of what constitutes female or minority "control." In the nationwide auction, $50.1 \%$ equity ownership by women or minorities was required, but in the regional auction, women and minorities could create control groups which owned as little as $25 \%$ of equity as long as the group owned more than half of the voting stock. Implementation of Section 309(j) of the Communications Act-Competitive Bidding, 9 F.C.C.R. 5306, 5307 (1994) (Order on Reconsideration, PP Docket No. 93 253) [hereinafter Order on Reconsideration].

${ }^{50}$ MiLGROM supra note 46, at 27. A designated bidder willing to pay $\$ 100$ million for a license could bid as much as $\$ 167$ million.

51 The installment plan was available to all "small businesses, including small businesses owned by minorities and/or women, on all regional licenses." Order on Reconsideration, supra note 49. The FCC announced the small business installment plan prior to the nationwide auction. See Third Report \& Order, supra note 20, at 2978-79. After the nationwide auction, the FCC allowed designated bidders that did not qualify as small businesses to pay by installments at an interest rate "equal to the rate for ten-year treasury obligations, plus 2.5 percent." Order on Reconsideration, supra note 49. In the regional narrowband auction, however, the only serious bidders that qualified as small businesses were also designated bidders (i.e., Benbow PCS Ventures, Constant Touch Communication, InstaCheck Systems, PCSD, and Lisa-Gaye Shearing). 
the licenses' award.$^{52}$ In contrast, the FCC required a winning small designated bidder to pay 10 percent at the auction close and only 10 percent more upon the award of the license. ${ }^{53}$ The remaining 80 percent would be financed by the government at the ten-year treasury bill rate of 7.5 percent. The designated bidder would only owe interest for the first two years and then would make equal quarterly installments for the next eight years to pay off the remaining interest and principal. ${ }^{54}$

Like the bidding credit, this installment program represented a significant bidding subsidy, because designated bidders could not borrow from private lenders on such favorable terms. The size of the subsidy can be calculated by discounting the installment payments to present value using a risk-adjusted interest rate. Finance economists equate the risk-adjusted interest rate with the market rate-in this case, the rate designated bidders would have to pay private lenders. Since private lenders possibly discriminate against designated bidders ${ }^{55}$ the rate they are forced to pay in the market may not represent the true risk of nonpayment. ${ }^{56}$

Determining the appropriate risk adjustment with any kind of precision is extremely difficult. At most, we know that the government was extending credit as a secured lender with a 20 percent equity cushion. If a designated bidder defaulted, the government could easily foreclose and resell the licenses, but their resale value would be uncertain. Therefore, the government's primary risk as lender is that the licenses may be worth less than 80 percent of the auction price and that the proceeds of subsequent resale would not repay the government's loan. Much of this risk, however, may be diversifiable and therefore does not justify a higher risk premium. ${ }^{57}$ In order to crudely estimate the installment subsidy, we assume that the risk-adjusted market rate for designated bidders would have been 12 percent -4.5 percentage points higher than the 7.5 percent ten-year treasury rate that the government actually charged. ${ }^{58}$ We chose 12 percent because it approximates the actual cost of secured financing for two of the narrowband bidders (as well as the cost of funds for broadly similar high technology organizations). ${ }^{59}$

52 The FCC typically awards licenses within three months of the auction's close. Cramton, supra note 2, at 7.

53 Third Report \& Order, supra note 20, at 2978.

${ }^{54}$ Order on Reconsideration, supra note 49, at 5307.

${ }^{55}$ When considering an installment subsidy for designated bidders, the FCC found that, in passing the Small Business Credit and Business Opportunity Enhancement Act of 1992, Pub. L. No. 102-366 (1992), Congress . . recognized that these funding problems are even more severe for minority and women-owned businesses, who face discrimination in the private lending market. For example, Congress explicitly found that businesses owned by minorities and women have particular difficulties in obtaining capital and that problems encountered by minorities in this regard are "extraordinary." A number of studies also amply support the existence of widespread discrimination against minorities in lending practices. Fifth Report \& Order, supra note 46, at 5573.

${ }^{56}$ This suggests that the interest rate subsidy benefits the designated bidders more than it costs the government. This would be true if lenders demanded a risk premium of $8 \%$ even though true nondiversifiable risk would only justify a four-point premium.

57 The Capital Asset Pricing Model suggests that risk premia should only compensate owners for risk that they cannot avoid by diversification. Richard A. Brealey \& Stewart C. MYers, PrinCiPles of Corporate FinANCE 161-66 (4th ed. 1991).

58 The 10-year treasury note rate itself overstates the risk-free rate: Treasury notes pay interest only at maturity, while the auction installment plan requires higher repayment levels in earlier years, when a lower risk-free rate would obtain.

${ }^{59}$ PageNet, a substantial paging firm, had a bond maturing in 2002 with a yield of $11.75 \%$ at the time of the auction. Moody's Investor Service, Corporate Bonds (U.S.), MOODY's BOND RECORD, June 1995, at 81. The largest bidder's approximate cost of debt was $12 \%$. Telephone Interview with Steve Lerner, Financial Analyst for PCSD. 
FiguRE 1: PRESENT VALUE OF INSTALLMENT AND BIDDING CREDIT SUBSIDIES ${ }^{60}$

${ }^{60}$ The present value of an installment subsidy for a particular risk-adjusted interest rate was calculated assuming that the government received $20 \%$ of nominal bid immediately, $7.5 \%$ of the nominal bid after both the first and second year, and $8.125 \%$ of the nominal bid in each of the remaining eight years. This cash flow was then discounted to present value for particular interest rates using the formula: present value of year $n$ cash flow $=($ year $n$ cash flow $) /(1+\text { risk - adjusted interest rate })^{n}$. The present value of all cash flows was then expressed as a percentage of the nominal bid. The line representing the present value of the installment subsidy and the bidding credit (expressed again as a percentage of the nominal bid) is simply $40 \%$ of the previous calculation. 


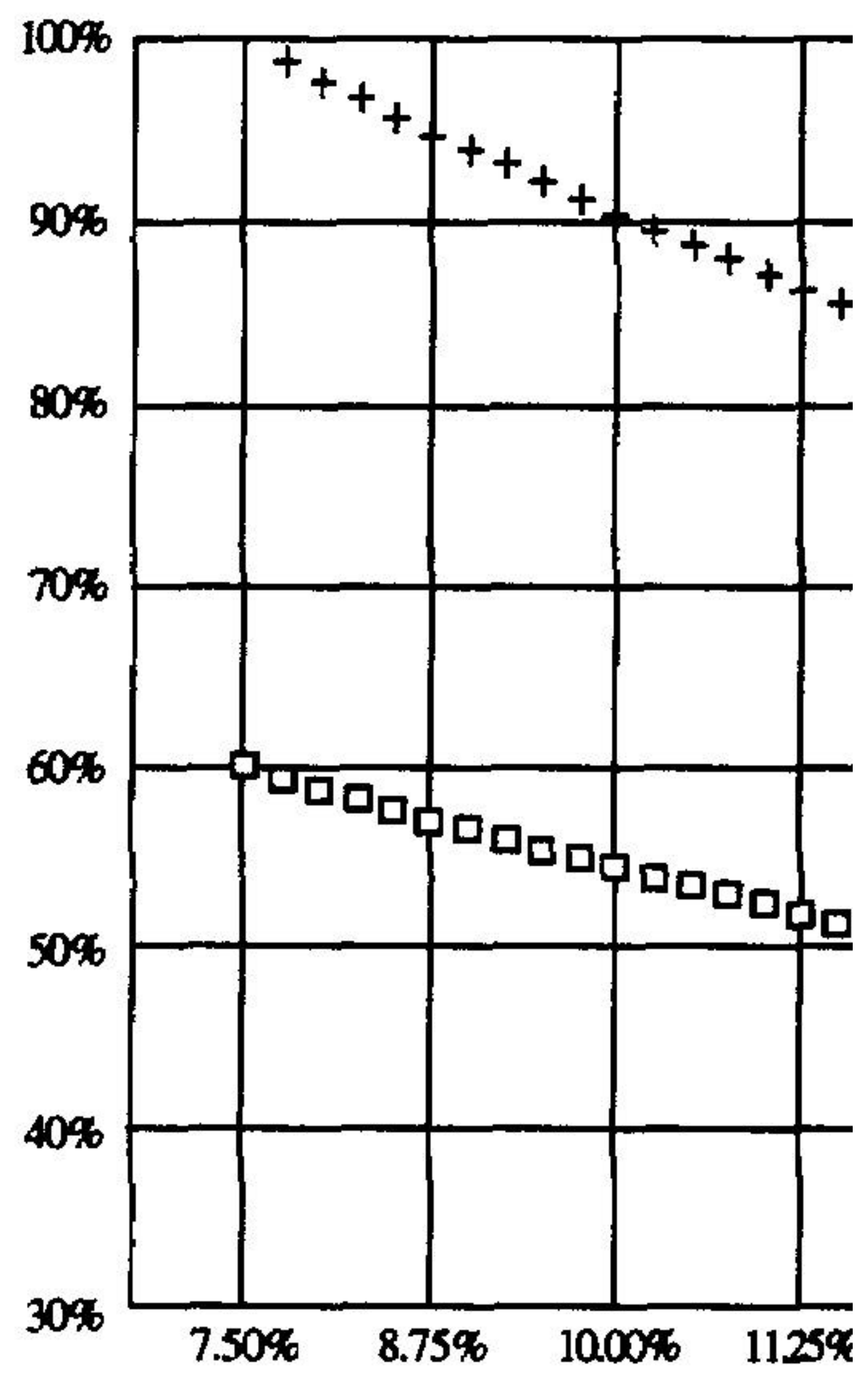


To illuminate the effect of this assumption on the size of affirmative action subsidies, Figure 1 represents estimates of the present value of the installment and of bidding credit subsidies for a range of possible riskadjusted interest rates. The top line depicts how the installment subsidy alone affects the present value of designated bidders' payments, while the lower line depicts the combined effect of the installment subsidy and the 40 percent bidding credit. ${ }^{61}$ At a 12 percent risk-adjusted rate, the present value of the installment payments equals 84.2 percent of the amount financed. This is the proportion of a winning bid that the government would receive if a designated bidder won any of the twenty regional licenses to which only the installment subsidy applied (i.e., Frequency Blocks 1, 3, 4, and 5). As for the ten set-aside licenses (Blocks 2 and 6), because of the combined effect of the installment subsidy and the 40 percent bidding credit, the government only receives 50.5 percent of the winning bids. ${ }^{62}$

\section{B. The Impact of Affirmative Action}

1. Comparing the nationwide and regional results.

Twenty-eight bidders participated in the regional narrowband auction; by round 12, only the twelve firms listed in Table 2 remained. Of these twelve, nine won licenses when the auction ended after 105 rounds.

TABle 2. BidDers AFter Round 12 In REgIONAL NARROWBAND AUCTION

\begin{tabular}{ll}
\hline Non-Designated Bidders: & Designated Bidders: \\
\hline Advanced Wireless Messaging (Advanced Wireless) & Benbow PCS Ventures, Inc. (Benbow) \\
AirtTouch Paging (AirTouch) & Constant Touch Communications, Inc. (Constant) \\
Ameritech Mobile Services, Inc. (Ameritech) & Insta-Check Systems, Inc. (InstaCheck) \\
MobilMedia PCS, Inc. (MobileMedia) & PCS Development Corporation (PCSD) \\
PageMart II, Inc. (PageMart) & Lisa-Gaye Shearing (Shearing) \\
Radiofone Nationwide Paging Service (Radiofone) & \\
Westlink Licensee Corporation (Westlink) & \\
\hline
\end{tabular}

Two aspects of the auction outcome (Table 3) stand out: (1) four of the six frequency blocks sold as nationwide aggregates, and (2) eleven of the thirty licenses were sold to designated bidders. Not only did designated bidders win all ten of the "effectively set aside" licenses, but InstaCheck prevailed on the Block 5South license, even though the 40 percent bidding credit did not apply.

\footnotetext{
61 The lower line is simply $60 \%$ of the upper line.

${ }^{62}$ As shown in Figure 1, if the appropriate risk-adjusted interest rate were 18\%, the present value of the installment payments would be $69.4 \%$ and the value with both installment and bidding subsidies would be $41.6 \%$.
} 
TABLE 3. FinAL OUTCOME IN REgIONAL NARROWBAND AUCTION

\begin{tabular}{|c|c|c|c|c|c|c|c|c|c|}
\hline \multicolumn{10}{|c|}{ (All values are net of applicable installment subsidies and bidding credits.) } \\
\hline \multirow{2}{*}{$\begin{array}{l}\text { Freq } \\
\text { Block }\end{array}$} & \multirow{2}{*}{$\begin{array}{l}\text { Type } \\
(\mathrm{kHz})\end{array}$} & \multicolumn{5}{|c|}{ Winning Bidder by Region } & \multirow{2}{*}{$\begin{array}{c}\text { Present } \\
\text { Value of } \\
\text { Auction } \\
\text { Revenue } \\
(\$ \mathrm{M})^{63}\end{array}$} & \multirow{2}{*}{$\begin{array}{c}\$ \text { per } \\
\text { MHz- } \\
\text { pop }\end{array}$} & \multirow{2}{*}{$\begin{array}{c}\text { Percent } \\
\text { Premium } \\
\text { over } \\
\text { Nationwide }\end{array}$} \\
\hline & & Northeast & South & Midwest & Central & West & & & \\
\hline 1 & $50 / 50$ & \multicolumn{5}{|c|}{$\langle\longrightarrow$ PageMart won all regions $\longrightarrow>$} & 92.6 & 3.67 & 15.7 \\
\hline $2^{* * *}$ & $50 / 50$ & \multicolumn{5}{|c|}{ PCS Development* won all regions } & 76.6 & 3.03 & -4.3 \\
\hline 3 ** & $50 / 12$ & \multicolumn{5}{|c|}{ MobileMedia won all regions } & 53.7 & 3.40 & 13.4 \\
\hline 4 & $50 / 12$ & \multicolumn{5}{|c|}{ Advanced Wireless won all regions } & 53.6 & 3.40 & 13.3 \\
\hline 5 & $50 / 12$ & Air Touch & InstaCheck* & Ameritech & AirTouch & AirTouch & 49.6 & 3.14 & 4.7 \\
\hline 6 6** & $50 / 12$ & Shearing* & Shearing* & Shearing* & Benbow* & Benbow* & 44.8 & 2.84 & -5.4 \\
\hline & & & & & & Total & 370.9 & 3.26 & 6.2 \\
\hline
\end{tabular}

* Designated bidder (Woman/Minority bidder)

** Woman/Minority bidder received a 40\% bidding credit on Blocks 2 and 6.

The present value of the government revenue-after taking account both the bidding credits and installment subsidies-was approximately $\$ 371$ million. Bidders paid an average of $\$ 3.26$ per MHz-pop, ${ }^{64}$ but as in the earlier nationwide auction, the 50/50 licenses were worth more per MHz-pop than the 50/12 ones. ${ }^{65}$ Not surprisingly, after taking into account the bidding credit and the installment subsidy, the cost per MHz-pop of licenses purchased by designated bidders was lower than that of analogous licenses purchased by unsubsidized bidders.

The regional auction did, however, produce one surprising result: The price per MHz-pop was 6.2 percent higher than the price paid by bidders in the nationwide auction that occurred just three months earlier. This increase in the regional narrowband auction represents more than a $\$ 21$ million increase in government revenue.$^{66}$ PageMart, MobileMedia, and Advanced Wireless paid significantly more for national aggregations than winners paid for identical licenses in the earlier auction. The increased prices in the regional auction are surprising because it is difficult to understand why the winners in the regional auction did not bid more when they participated in the national auction three months earlier.

Indeed, evidence from other auctions suggests that, when similar items are sold in sequence, the later items usually sell less than the earlier items. ${ }^{67}$ This "declining price anomaly" has been observed in auctions for wine,

\footnotetext{
${ }^{63}$ When non-designated bidders prevailed, the "Present Value of Auction Revenue" is simply their winning bids. When designated bidders prevailed, the figure is their winning bids multiplied by the appropriate discount factor. For all the licenses on Blocks 2 and 6, this discount factor was 50.5, which reflects the $49.5 \%$ installment subsidy and bidding credit. See text accompany note 62 supra. Estimating the present value of the auction revenue for InstaCheck's purchase of the Block 5-South license is complicated in two respects. First, because the 40\% bidding credit did not apply to Frequency Block 5, only the $84.2 \%$ discount factor (reflecting the installment subsidy alone) was deducted from InstaCheck's $\$ 8$ million final bid. Second, PCSD's crossover bidding on Block I not only induced PageMart to bid up the price of this Block 5 license, but later PCSD's decision to stop bidding on Block I induced PageMart to withdraw a prevailing \$10.129 million bid on this Block 5 license and consequently, as required by the auction rules, to incur a $\$ 2.129$ million penalty (the difference between its withdrawn bid and Instacheck's winning $\$ 8$ million bid). Accordingly, the present value of the revenues generated for Block 5-South license was calculated to be: $(\$ 8$ million $x 0.842)+\$ 2.129$ million $=\$ 8.9$ million. See Table 5 infra

All bidding data referred to in this article are available on the Internet either on the World Wide Web (http://www.fcc.gov) or by accessing fcc.gov by anonymous ftp. Information is organized in text or database formatted files. The data for round 12 , for example, is at ftp://ftp.fcc.gov/pub/Auctions/ PCS/Narrowband/ Regional/Round-012/s3-12.txt.

64 "Dollars per MHz-pop" is calculated by dividing the total revenue ( $\$ 370.9$ million) by both the population (252.6 million) and the number of megahertz auctioned (0.45). Population as of 4/1/90 from FEDERAL COMMUNICATIONS COMMISSION, BIDDER'S INFORMATION PACKAGE FOR THE REgional NaRROWBAND PCS AuCTION 3 (1994) (citing BUREAU OF THE CENSUS, U.S. DEPARTMENT OF COMMERCE STATISTICAL ABSTRACT OF THE UNITED STATES: 1993. at 822 (113th ed. 1993)). For a given bandwidth, the "dollars per MHz-pop' measures how much a bidder is willing to pay per potential customer for a $\mathrm{MHz}$ license. For example, since Frequency Block I had a total width of $0.1 \mathrm{MHz}(50 \mathrm{kHz}$ incoming $+50 \mathrm{kHz}$ outgoing $=100 \mathrm{kHz})$, a $\$ 3.67$ price per MHz-pop suggests that PageMart was wiring to pay approximately 37 cents per potential customer for $50 / 50$ nationwide coverage.

${ }^{65}$ In the nationwide narrowband auction, the 50/50 licenses sold for $\$ 3.17$ per MHz-pop and the 50/12 licenses sold for $\$ 3.00$ per MHz-pop. Nationwide auction data is located at ftp://ftp.fcc.gov/pub/ Auctions/PCS/Narrowband/Nationwide/finalbid . txt.

${ }^{66}$ If the nationwide prices per MHz-pop had been realized in the regional auction, the two 50/50 frequency blocks would have each sold for $\$ 80.0$ million and the four 50/12 frequency blocks would have sold for $\$ 47.3$ million—generating $\$ 349.3$ million, $\$ 21.6$ million less than the actual regional revenues shown in Table 3 supra.

${ }^{67}$ Orley Ashenfelter, How Auctions Work for Wine and Art, J. ECON. PersPective, Summer 1989, at 23, 29-30 (describing the price decline anomaly at wine auctions).
} 
timber, cattle, and satellite licenses. ${ }^{68}$ Game theory provides three different reasons why we should have expected prices in the regional auction to be lower than the earlier national auction: risk-averse bidders, marketing advantages, and the difficulty of aggregating regional licenses. First, risk-averse bidders prefer the sure gains of winning today to the uncertain prospects of winning tomorrow. Such bidders, therefore, would be willing to bid more in the first auction than the expected sale price in the later auction. ${ }^{69}$ Second, early resolution of uncertainty regarding a firm's spectrum capacity provides a tremendous marketing and development advantage. Being first to market in an unproven industry with substantial network externalities and significant switching costs has enormous value. ${ }^{70}$ Third, because the later licenses were regional, a firm wanting to create a national paging system would probably pay a premium to avoid the aggregation difficulties presented by buying five individual regional licenses on a single frequency block. ${ }^{71}$

Based on the above, we would expect prices in the regional auction to be lower than those in the nationwide auction. What, then, explains the $\$ 21$ million increase in regional prices? We contend that the rise in prices was caused by the FCC's unexpected announcement after the nationwide auction that a substantial increase in the affirmative action subsidy would apply to subsequent auctions. As discussed above, ${ }^{72}$ affirmative action can create more bidding competition by enhancing both intergroup and intragroup competition, and it can thereby increase the seller's expected revenue. ${ }^{73}$ The increase in affirmative action is an attractive hypothesis because it alone is a key variable that changed in the interim between the nationwide and regional auctions. ${ }^{74}$

A simple comparison between nationwide and regional prices, however, does not provide very powerful evidence that affirmative action alone effected the price change, because other factors might have caused the regional prices to increase. For example, regional prices may have been higher not because of designated bidder competition, but rather because of the presence of non-designated bidders with regional strategies. Bidders that only sought regional licenses would not have provided direct bidding pressure in the nationwide auction, but would have been able to bid up the winning prices in the regional auction. ${ }^{75}$ However, since three of the four nonset-aside regional frequency blocks were sold as nationwide aggregations, it is apparent that many of the nondesignated firms that won in the regional auction could have purchased comparable licenses in the nationwide auction at lower prices. $^{76}$ Indeed, PageMart, MobileMedia, and Advanced Wireless did participate in the nationwide auction, but dropped out at prices well below those they were willing to pay three months later in the regional auction. ${ }^{77}$ Thus, for regional demand adequately to explain the increased regional prices, it must be that these firms did not anticipate the higher regional prices.

Another possibility is that bidders paid more in the regional auction because they were capital constrained in the nationwide auction: Since the nationwide prices exceeded government estimates, it is possible that bidders failed to bring enough capital to the nationwide auction. Under this theory, prices were higher in the regional auction simply because bidders amassed larger war chests. This capital constraint hypothesis, however, is

${ }^{68}$ R. Preston McAfee \& Daniel Vincent, The Declining Price Anomaly, 60 J. ECON. THEORY 191, 192 (1993). There are exceptions to declining prices: Prices tended to increase in the sequential sale of Israeli cable television licenses. Neil Gandal, Sequential Auctions of Israeli Cable Television Licenses: An Empirical Test for interdependent Valuations (May 25, 1995) (unpublished manuscript on file with the Stanford Law Review). Apparently firms were willing to pay more for later licenses because of complementarities. Id.

${ }^{69}$ McAfee \& Vincent, supra note 68, at 193 (noting that "[f]or a risk averse bidder . . . the randomness of utility from the final auction reduces his value and therefore increases the bid he is willing to make in the first period").

${ }^{70}$ Fast resolution of spectrum allocation is so important that designated bidders recently petitioned the FCC to eliminate certain prospective affirmative action subsidies, which were to apply to the second broadband auction, in order to avoid litigation over the subsidies' constitutionality. Text of “Affirmative Action Review' Report to President Clinton Released July 19, 1995, 1995 Daily Lab. Rep. (BNA) No. 139, § 11.1.1 (July 20, 1995).

${ }^{71}$ See text accompanying notes 112-116 infra (discussing partial aggregation risk at regional auction).

${ }^{72}$ See text accompanying notes 30-33 supra.

${ }^{73}$ For affirmative action to have caused the price increase, however, its existence or magnitude must have been unanticipated. If the increased demand for licenses caused by increased affirmative action in the regional narrowband auction had been anticipated, bidders who sought nationwide aggregates of regional licenses (e.g., PageMart, MobileMedia, and Advanced Wireless) would have bid more aggressively in the nationwide auction. Some auction participants might have anticipated that the FCC would enhance the affirmative action subsidies in the subsequent auction after designated bidders exited en masse following the early rounds of the nationwide auction, but we believe that, even if that were the case, they did not anticipate the extent of the subsidy increase.

${ }^{74}$ After considering affirmative action's effect on revenue, we describe and critique three alternative explanations for the increased revenue-none of which proves satisfactory. See text accompanying notes 96-111 infra.

${ }^{75}$ For an example of how regional demand can enhance bidding competition, see McMillan, supra note 45, at 156 n.10.

${ }^{76}$ In the nationwide auction, 50/SO licenses sold for an average of $\$ 80$ million, and 50/12 licenses cost an average of $\$ 47.3$ million. In the regional auction, the non-set-aside 50/50 aggregation sold for \$92.6 million, while the non-set-aside 50/12 aggregations sold for an average of $\$ 52.3$ million.

${ }^{77}$ See Cramton, supra note 44, at 296-317. Tables VIIA-D and VIIIA-G give the national auction bids of PageMart (bidder ID 9683), Advanced Wireless (alias American Portable, bidder ID 5403), and Mobile Media (bidder ID 1666). PageMart dropped out of the 50/50 bidding at $\$ 79.0$ million, but paid $\$ 92.6$ million in the regional auction; Advanced Wireless dropped out of the 50/12 bidding at $\$ 45.9$ million, but paid $\$ 53.6$ million in the regional auction; Mobile Media dropped out of the 50/12 bidding at $\$ 44$ million, but paid $\$ 53.7$ in the regional auction. 
inconsistent with the bidding behavior of some relatively liquid corporations who dropped out of the national auction, yet paid more for a national aggregation in the regional auction. In particular, AirTouch —with equity worth more than $\$ 10$ billion-had substantial resources at its disposal, ${ }^{78}$ and in all likelihood could have bid more in the nationwide auction, but chose not to.

While neither the regional demand nor the capital constraints theories adequately explain the higher prices in the regional auction, we still do not wish to base our affirmative action theory on the simple comparison between the regional and national auctions. Instead, the next section provides direct evidence from an analysis of designated and non-designated bidding behavior in the regional narrowband auction that affirmative action increased government revenue.

\section{The impact of designated crossover bidding.}

A simultaneous auction is somewhat like a game of musical chairs. The auction continues as long as there are more bidders than items to be auctioned. If three identical goods are being simultaneously auctioned, the price at which the fourth highest valuer drops out determines the price that the top three valuers will pay. For example, consider five bidders (A, B. C, D, and E) who have reservation prices of $\$ 50, \$ 40, \$ 30, \$ 20$, and $\$ 10$ respectively. If we held an ascending simultaneous auction with $\$ 1$ bid increments for three identical chairs, we would expect that bidders $\mathrm{A}, \mathrm{B}$. and $\mathrm{C}$ would each win a chair for $\$ 21$. D's willingness to bid $\$ 20$ creates excess demand at prices less than $\$ 21$. If $\mathrm{D}$ were not present at the auction, $\mathrm{E}$ would be the fourth highest valuer, and the three chairs would sell for only $\$ 11$ each. In this example, then, $D$ 's presence increases the total auction revenues by $\$ 30$ (from $\$ 33$ to $\$ 63$ ). Identifying the "marginal excess demand"-i.e., the last bidder to drop out—allows us to infer how the presence of certain bidders affected price. ${ }^{79}$

The bidding data from the regional auction provide strong evidence that designated bidders caused the excess demand responsible for increasing government revenues by approximately $\$ 45$ million. By round 12 (of the 105 rounds) when bidders had reached 70 percent of the ultimate price, all of the ultimate non-designated winners (PageMart, MobileMedia, Advanced Wireless, AirTouch, and Ameritech) held high bids on the licenses that they would ultimately buy ${ }^{80}$ and virtually all other non-designated bidders had dropped out of the action ${ }^{81}$ Because the non-designated bidders that were still eligible held high bids for the licenses they desired by round 12, they had no incentive to raise prices any more.

The dramatic exit of the excess non-DE demand is illustrated in Figure 2. This figure shows the average excess demand for both 50/50 and 50/12 licenses for different auction prices (expressed as a percent of the final price). The step function shows how the excess demand by non-designated bidders was gradually extinguished as prices rose. When the auction prices had reached $20 \%$ of their final level, there were two excess non-designated bidders for each license type in each region. When the prices rose above $30 \%$ of the final price, excess demand by non-designated bidders fell from two to one for each license type (50/50 or 50/12). Most importantly, when prices rose above $70 \%$ of the final prices, there was no excess demand by non-designated bidders for any license. Figure 2, then, shows that designated bidders were responsible for the last $30 \%$ of auction revenue for the simple reason that none of the remaining non-designated bidders had an incentive to increase prices.

\section{FiguRE 2: EXCESS DEMAND BY NON-DESIGNATED ENTITIES} (REVENUE WEIGHTED) $^{\mathbf{8 2}}$

\footnotetext{
${ }_{78}^{78}$ On March 20, 1995, AirTouch's stock was worth $\$ 13.5$ billion. See http://www.streetnet.com/airtouch.

${ }^{79}$ Milgrom uses a similar analysis to identify the marginal bidders who determined the prices of the first broadband auction MiLGROM, supra note 46, at 45-46.

${ }^{80}$ The one exception to this was AirTouch, a non-designated bidder which held prevailing bids in Frequency Block 5 in the Northeast, South, and West regions but ultimately won licenses for Frequency Block 5 in the Northeast, Central, and West regions. See note 63 supra. However, as discussed at note 87 infra and accompanying text, shifting demand from the South to the Central regional licenses would not increase the auction price.

${ }^{81}$ The only non-designated bidders that were still active, but would not ultimately purchase a license, were Westlink, which made its last new bid in round 15, and Radiofone, which made its last new bid in round 44.

${ }^{82}$ Figure 2 is derived as follows. First, for each region and type of license (50/50 and 50/12), the highest bids that each nondesignated bidder placed on the license(s) are identified and sorted in decreasing order. For example, consider the Northeast Block I license. The highest bids by the final two non-designated firms to bid on this 50/50 license were $\$ 17.5$ million (PageMart) and $\$ 12.6$ million (McCaw). From these bids, we conclude that at a price of $\$ 12.6$ million there is excess demand for one Northeast 50/50 license by a nondesignated bidder. This identifies the top step of the excess demand function.

To aggregate the excess demand curves across license type and region, we state the price dimension as the fraction of the final bid. In the case of the Block 1 Northeast 50/50 license, the top step then occurs at 12.6/17.5 =72\%. That is, when the price is above $72 \%$ of the final price, there is no excess demand by non-designated bidders. For prices below $72 \%$ of the final price, there is non-designated excess demand of at least one. These individual demand curves are then aggregated in the usual way.

Figure 2 shows the average excess demand where the licenses are weighted by revenue. When only aggregated across regions, but not across license type (50/50 or 50/12), the excess demand curves are nearly identical to the curve in Figure 2 . Excess demand by nondesignated bidders falls to zero (on average) when prices are greater than $70 \%$ of the final price. Hence, by this measure, $30 \%$ ( $\$ 70$ million)
} 
of the revenue collected in the auction comes from bidding by designated bidders. This number is bigger than the $\$ 45$ million number we determine in Table 4, because here the assumption is that by placing a highest bid of $\$ 12.6$ million, McCaw is expressing a willingness to pay $\$ 12.6$ million, but no more. In Table 4, the alternative assumption applies - that McCaw is willing to bid all the way up to the response to the $\$ 12.6$ million that caused McCaw to drop out. In fact, since bids increase in a discontinuous fashion, it is impossible to know how high McCaw would be willing to go. The only known fact is that McCaw dropped out after placing a final bid of $\$ 12.6$ million. The actual increase in revenue caused by the designated firm bidding is probably between the overly conservative figure of $\$ 45$ million and the overly optimistic figure of $\$ 70$ million. 


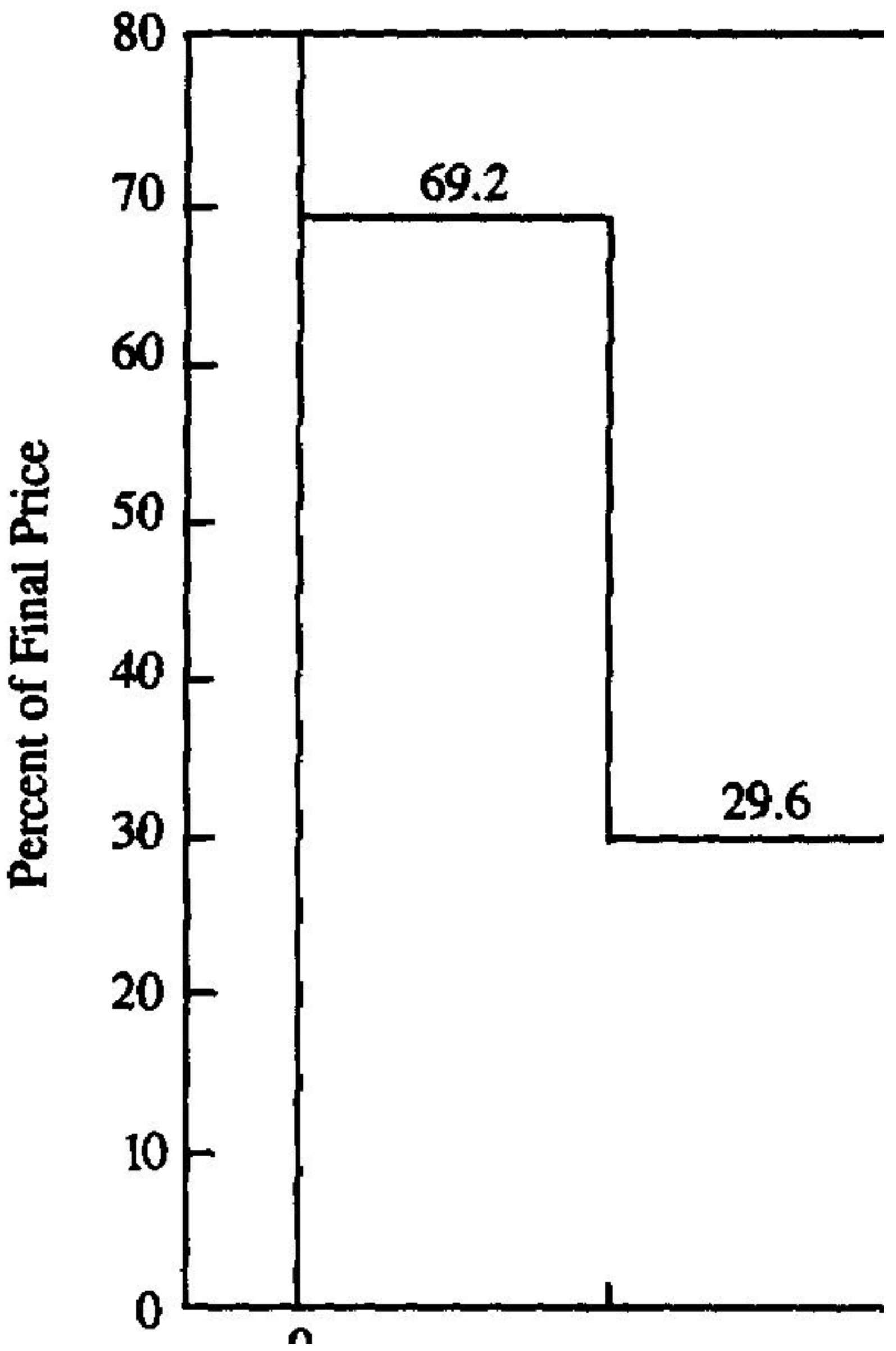


All of the excess demand came from designated bidding. The two frequency blocks effectively set aside for designated bidders by the 40 percent bidding credit (Blocks 2 and 6) were insufficient to satisfy the demands of the five designated bidders still in the auction: PCS Development, Shearing, Benbow, InstaCheck, and Constant. These designated bidders upped the price of the ten set-aside licenses to the point where it became attractive for them to cross over and bid on the licenses for which only the installment subsidy was available. Specifically, in round 18 (after Benbow and PCSD had bid up the prices on Frequency Block 2), PCSD crossed over and bid against PageMart for Frequency Block I licenses. ${ }^{83}$ PCSD raised the price on the Block 1 licenses thirteen times before dropping out. PageMart ultimately won all the Block 1 licenses, but PCSD's bidding raised the price on Block 1 licenses by $\$ 16.4$ million, as shown in Table 4. PCSD could afford to push the bidding on Block 1even without the 40 percent bidding credit—because it still would receive the installment subsidy, permitting payment of only 84 percent of a winning bid. Moreover, the 40 percent bidding credits, which effectively set aside the Block 2 licenses, allowed PCSD to cross over and bid against PageMart without fear that PageMart would retaliate by bidding up the price of Block 2 licenses ${ }^{84}$ Our inference that designated crossover bidding caused the puce increase is particularly strong because designated bidders were the only firms to bid against PageMart for Block I licenses after round 12..$^{85}$

Although Instacheck also bid for Block 1 licenses, we attributed the price increase to PCSD's crossover because InstaCheck did not ultimately drop out of the bidding for the non-set-aside licenses. Instead, at various times in the auction, InstaCheck merely shifted its constant demand for a single license by bidding on a variety of licenses one at a time. ${ }^{86}$ Accordingly, InstaCheck's crossover bidding did not represent excess demand but merely shifted demand: Instacheck never reduced its demand for a non-set-aside license as it ultimately purchased a South license for Frequency Block 5. However, PCSD's crossover demand for non-set-aside licenses was excess in the sense that PCSD reduced its demand (to zero) before the auction's end. As in our earlier example of musical chairs, it is only excess demand that drives up auction prices. ${ }^{87}$ PCSD's crossover bidding was therefore crucial in driving up the ultimate sale price of Block 1 licenses because it was the last bidder to reduce its demand for the non-set-aside licenses.

${ }^{83}$ Compare ftp://ftp.fcc.gov/pubs/Auctions/PCS/Narrowband/Regional/Round-01 8/s3—I 8.txt with Round—017/s3-17.txt. The competition between Benbow and PCSD had increased the combined price of Frequency Block 2 Northeast and South licenses to \$49.94 million by round 17, which, even after deducting the $40 \%$ bidding credit, was still more than PCSD's $\$ 29.64$ million bid on the same two regional Frequency Block 1 licenses in round $18(29.64<(49.94 \times 0.6)=29.97)$.

${ }^{84}$ MiLGROM supra note 46, at 33.

${ }^{85}$ PCSD raised PageMart 13 times, and Instacheck raised PageMart three times.

${ }^{86}$ InstaCheck was active in crossover bidding raises in each of the non-set-aside frequency blocks: three times in Block 1, four times in Block 3, three times in Block 4, and 10 times in Block 5.

${ }^{87}$ In the earlier example, see text accompanying note 79 supra, even though the fourth highest valuer $(D)$ controlled the auction price, we would expect to observe "shifted" demand from the ultimate winners $(A, B$. and $C)$. For example, if in the middle of the auction $A, B$. and $C$ each held a high bid of $\$ 15$ on one of the chairs, $D$ might raise the price of Chair I to $\$ 16$, displacing $A$ 's previous high bid. Instead of bidding $\$ 17$ on Chair 1, $A$ might temporarily shift its demand and bid $\$ 16$ on Chair 2, thereby displacing $B$ 's previous high bid. Likewise $B$ might shift its demand and bid $\$ 16$ on Chair 3, displacing $C$. $C$ might in turn raise the price of any one of the chairs to $\$ 17$. Shifting demand would continue until $D$ finally dropped out of the market after bidding its reservation price of $\$ 20$. 


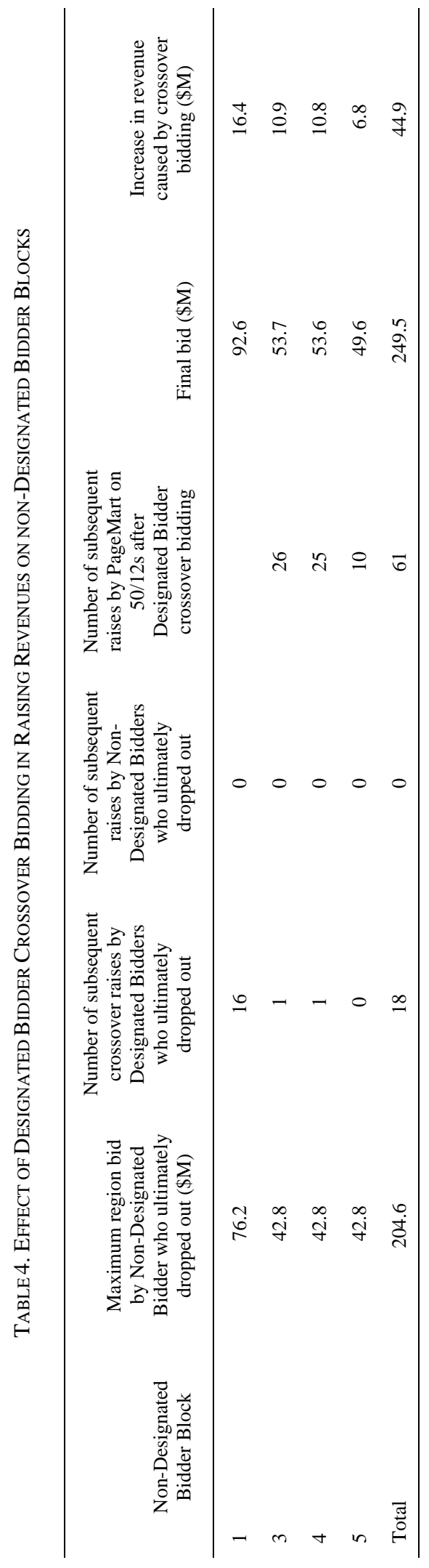


PCSD's crossover bidding on Frequency Block 1 also predictably led to price increases for the other non-setaside frequencies (Blocks 3, 4, and 5). PageMart, facing unexpected competition from PCSD on Block 1 licenses (and unable to retaliate by bidding up prices of Frequency Blocks 2 or 6), responded by repeatedly shifting its demand to Blocks 3, 4, and 5. As shown in Table 4, PageMart shifted its demand from the Frequency Block 1 50/50 licenses to the 50/12 licenses in Frequency Blocks 3, 4, and 5, raising the bid on these latter licenses 61 times and increasing their final price by $\$ 28.5$ million. ${ }^{88}$ PageMart's shifted demand was the only bidding that raised the prices of the 50/12 licenses in the last 60 rounds of the auction (all other firms bidding on 50/12 licenses during the last 60 rounds ultimately purchased 50/12 licenses), ${ }^{89}$ and PageMart only shifted its demand to the 50/12 licenses because of PCSD's crossover bidding on the Frequency Block $150 / 50$ licenses.

Table 4 shows that the only excess demand for the last $\$ 44.9$ million of the auction increases came from designated bidders. As shown in the column labeled "Number of subsequent raises by non-designated bidders who ultimately dropped out," none of the bidding that gave rise to the last $\$ 45$ million in revenue came from nondesignated bidders who ultimately dropped out. Had affirmative action not created excess designated bidder demand, the ultimate winners would not have needed to bid above the levels listed in the "Maximum region bids by non-designated bidders who ultimately dropped out" column.

InstaCheck's purchase of a non-set-aside license is also strong evidence that designated bidding determined the final price of the non-set-aside licenses..$^{90}$ Once excess demand for the set-aside licenses drove up their prices to the point where crossover bidding became attractive, the excess designated demand started setting the prices for both set-aside and non-set-aside licenses. Our theory that excess designated demand determined non-set-aside license pricing is confirmed by the similarity of the prices paid for the set-aside licenses (net of the 40 percent bidding credit) and the non-set-aside licenses. ${ }^{91}$

The crossover bidding effect on the regional auction can be summarized as follows:

(1) Excess demand by designated bidders for the set-aside frequency blocks (2 and 6) drove PCSD to cross over and bid up the price of Frequency Block 1.

(2) Crossover bidding by PCSD on Frequency Block 1 caused PageMart to bid up the price of Frequency Blocks 3, 4 , and 5.

(3) The auction ended when the bidding on Frequency Block 2 finally extinguished excess designated demandallowing PCSD to create a national aggregation of regional licenses on Frequency Block 2 so that it no longer needed to cross over and bid on Frequency Block 1.

By round 104, the bids were high enough to squelch the excess designated demand and, therefore, the impetus for crossover bidding-but only after this crossover bidding had increased the government's revenues by approximately $\$ 45$ million-or 12 percent of the government's total auction revenue. In short, PCSD's crossover bidding, and the shifted bidding it inspired, made the government a substantial sum of money.

\section{The impact of the set-aside licenses.}

The prior section demonstrated how crossover designated bidding on Frequency Blocks 1, 3, 4, and 5 increased auction revenue, but it did not discuss how affirmative action affected the price on the frequency blocks that were effectively set aside by the 40 percent bidding credit. To analyze these de facto set-asides, we need to estimate not only the effect of the set-asides on the prices designated bidders ultimately paid for Frequency Blocks 2 and 6, but also how the reduced supply affected the prices non-designated bidders ultimately paid for the non-set-aside frequencies.

One might initially suspect that affirmative action would have decreased the auction revenues for the set-aside licenses because the 40 percent bidding credits effectively precluded non-designated bidder competition. But, in

\footnotetext{
${ }^{88}$ From Table 4, $10.9+10.8+6.8=\$ 28.5$ million. The "Maximum region bids by lion-Designated Bidders who ultimately dropped out" was calculated by identifying the ultimate winner's response to the highest bid from a non-designated bidder who ultimately dropped out or reduced the number of licenses that it demanded. A license by license breakdown of Table 4 appears in Table 5 infra.

${ }^{89}$ As shown in Table 4, designated bidders on two occasions raised the price of non-set-aside 50/12 frequency blocks: Constant once raised the bidding on a Block 3 licenses (in round 17), and PCSD once raised the bidding on a Block 4 license (in round 28). This crossover bidding by designated bidders who ultimately reduced their demand shows even more directly how affirmative action raised prices.

${ }^{90}$ See Table 3 supra; see also Milgrom, supra note 46, at 30 ("The fact that a minority-owned bidder was able to acquire a license for which no discount was offered indicates that there was excess demand for the reserved licenses."). If excess non-designated demand had been determinative in pricing the non-set-aside licenses, designated bidders would have been able to buy set-aside licenses more cheaply than non-set-aside licenses.

${ }^{91}$ The prices of the set-aside bands net of the $40 \%$ bidding credit wee $1.7 \%$ higher than those of the non-designated bands and represented the minimum bid increment by which the non-designated bidders needed to exceed the designated bidders. Net revenue for the designated band $/ \mathrm{MHz}=(90.9+53.2) /(0.1+0.0625)=\$ 887 / \mathrm{MHz}$. Net revenue for the non-designated band $/ \mathrm{MHz}=(92.6+53.7+53.6+$ $50.8) /(0.1+(3 \times 0.0625))=\$ 872 / \mathrm{MHz}$. Comparing the designated and non-designated bands: $(\$ 887-\$ 872) / \$ 872=1.7 \%$. The price setting effect of the excess designated demand does not mean that designated bidders were not weaker bidders. Indeed, the installment subsidy by itself was substantial, reducing the present value of the designated bidders' payments to $84 \%$ of these net bid.
} 
the absence of affirmative action, allowing the excluded non-designated bidders to compete for the set-aside licenses would not have increased the winning bids for these licenses. Table 4 shows that the final excess demand by non-designated firms was extinguished when the bidding for the 50/50 block went above $\$ 76.2$ million and the bidding for the 50/12 blocks went beyond $\$ 42.8$ million. Allowing these excluded non-designated bidders to compete for the set-aside licenses would not have raised the price of set-aside licenses for the simple reason that - even after deducting the bidding credit and installment subsidy - the set-aside frequency blocks sold for more (Block 2 for $\$ 76.6$ million and Block 6 for $\$ 44.8$ million) than the excluded non-designated bidders were willing to pay. On these facts, it does not appear that setting aside Frequency Blocks 2 and 6 reduced their equilibrium price.

The 40 percent bidding credit acted as a safety net to insure a minimum amount of designated entity participation, but in the end this safety net was not needed. The designated demand was sufficient to compete away virtually all of this bidding credit—as the nominal prices on Blocks 2 and 6 were approximately 40 percent higher than on their non-set-aside counterparts. Indeed, the final auction bids superficially suggest that the installment subsidy did all the work - meaning that if only the installment credit had been granted, designated bidders would have still been strong enough to win eleven licenses and would have still pushed the bidding of the non-designated firms to the same level.

Yet this superficial analysis ignores how the "safety net insurance" of the 40 percent bidding credit may have induced designated entities (and their passive non-designated partners) to form and prepare for the auction. Knowing that there were at least 10 licenses effectively set aside may have induced many designated firms to undertake the fixed costs to organize, investigate, and finance auction participation. Having incurred these fixed costs, the designated firms created enough demand that they bid away virtually all of the 40 percent bidding credit, but the bidding credit may have played an important role in encouraging the firms to incur these costs. ${ }^{92}$

There is an important lesson here. The government can offer very substantial bidding credits to insure minimal minority and/or female participation often without increasing the cost of the subsidy. ${ }^{93}$ Guaranteeing a minimum amount of participation may induce stronger designated firms to form so that in the end the government need not pay off on the guarantee. ${ }^{94}$

In sum, the bidding data suggest that the 40 percent bidding credit did not reduce the price of the effectively set-aside licenses and, if anything, this large credit, by providing a type of insurance, may have induced stronger designated demand to form. The designated demand was so strong that even after taking account of both the bidding credit and the installment subsidy, the designated firms paid more for the set-aside blocks than the nondesignated firms were willing to bid. Since affirmative action did not reduce the government's revenue on the setaside licenses, the evidence that crossover DE bidding raised the price of the other licenses by $\$ 45$ million therefore constitutes our combined estimate of the revenue-enhancing impact of affirmative action. ${ }^{95}$

\section{Alternative Hypotheses}

Before accepting our $\$ 45$ million estimate, however, we consider three alternative hypotheses that might explain the auction's outcome. Our estimate is based on a crucial assumption that, in the absence of affirmative action, no bidder would have bid above the final price where the excess non-designated bidders dropped out of the auction. This assumption, however, might fail for three reasons:

\footnotetext{
${ }^{92}$ We consider whether the $40 \%$ bidding credit deterred non-designated firms from bidding at text accompanying noses 110-111 infra.

${ }^{93}$ This analysis is extended in Ian Ayres, Narrow Tailoring (March 16, 1995) (unpublished manuscript, on file with the Stanford Law Review)

${ }^{94}$ If the designated entities had not formed, the final bids on the non-set-aside block would almost surely have been lower. Although Table 4 estimated that without crossover bidding the 20 non-set-aside licenses would have sold for \$204.6 million-the price where excess non-designated demand stopped pushing up the bidding - if 50\% more licenses were offered to non-designated firms, then the prices on all the non-set-aside licenses would undoubtedly have been lower. Rather than the 21 st highest valuer's determining license prices, the $31 \mathrm{st}$ highest valuer would have determined the final price.

${ }^{95}$ One may be tempted to reduce the revenue increase by the effect the higher revenue has on tax receipts. For example the Congressional Budget Office routinely applies an offset of $25 \%$, which is the average marginal corporate tax rate. See CONGRESIONAL Budget OfFice, Budget Estimates: Current Practices And Alternative Approaches 8-9 (1995). (The 25\% offset is specifically mentioned in Emil M. Sunley \& Randall D. Weiss, The Revenue Estimating Process, TAX NotES, June 10, 1991, at 1302.) This would be the right thing to do if the larger amounts paid by firms reduced corporate taxes by $25 \%$ of the extra revenue. However, according to David P. Gamble, Vice President of PageNet, "The amount paid to the government does not change our tax position at all." Telephone Interview with David P. Gamble, Vice President of PageNet (February 9, 1996). Because of the enormous outlays in building a paging network, the paging companies rarely, if ever, show a profit that would be taxed. PageNet, the largest and most established paging company in she U.S has never paid corporate income tax. Hence, in the paging business the appropriate offset for lost corporate taxes should be much less than $25 \%$.
} 
(1) Non-Designated Bidders Hid in the Grass: The reservation prices of the non-designated bidders that dropped out may have been higher than their observed highest bidds-so that in the absence of affirmative action, these non-designated bidders may have forced up the bidding;

(2) Designated Bidders Would Have Bid Anyway: In the absence of affirmative action, the winning designated bidders may have still bid more than the prices at which the non-designated bidders dropped out; and

(3) Affirmative Action Chilled Non-Designated Bidder Participation: In the absence of affirmative action, the reservation prices of the non-designated bidders that did not participate may have been increased.

If any of these explanations are true, then our estimate of revenue enhancement would be inflated because our benchmark of what the winning prices would be in the absence of affirmative action would be too low.

Before considering each of these alternative hypotheses, however, it is important to emphasize that our $\$ 45$ million estimate does not depend on the earlier comparison with the nationwide auction. As suggested above, even though unexpected regional demand or capital constraints might explain why the regional prices were higher than the nationwide prices, these theories do not refute the evidence that all the excess demand responsible for the last $\$ 45$ million of bidding came from designated bidders. Our benchmark-the price at which nondesignated bidders dropped out of the auction —already takes into account the possibility that these bidders had unexpected regional demand ${ }^{96}$ or were less capital constrained. ${ }^{97}$ We now, however, consider three reasons why our excess demand benchmark may have understated the prices that would have prevailed in the absence of affirmative action.

\section{Hiding in the grass.}

Recall that PCSD crossed over to bid on non-set-aside licenses when the set-asides proved insufficient to satisfy its demand. If PCSD had not provided the excess demand, it is possible that a non-designated bidder would have stepped in at the lower prices and created excess demand by bidding on more licenses. If this were true, the excess demand of non-designated bidders would have been greater than we observed in the auction bidding; one or more of the non-designated bidders would have been "hiding in the grass"-bidding on fewer licenses than it actually preferred to buy at a given price. If non-designated bidders were hiding in the grass, then our inference that crossover designated bidding caused the $\$ 45$ million increase would be incorrect. In the absence of affirmative action, some of the non-designated bidders may have bid on a greater number of licenses and driven the prices at least part of the way toward those achieved through crossover bidding.

Hiding in the grass strategies usually assume that rivals have limited capital budgets: Hiding in the grass in early rounds may let a bidder buy a license more cheaply if its rivals commit too much of their limited budgets to other licenses and thereby lose the ability to bid as much against the hidden demand when the "snake" surfaces by bidding in later rounds. ${ }^{98}$ For example, consider an auction in which a forthright bidder has a limited budget of $\$ 100$ million and early in the auction holds high bids for three licenses at \$20 million per license. Under these assumptions, a snake bidder might delay revealing its interest in one of these licenses-even if its reservation price is $\$ 30$ million. By hiding in the grass for a number of rounds, the snake may induce the forthright bidder to commit more than $\$ 70$ million in bids on the other two licenses; the snake can then enter the bidding knowing that it can outbid the incumbent. Hiding in the grass is a rational strategy when a rival faces a firm budget constraint, and higher bids on one license by the rival necessarily reduce its ability to bid on other licenses.

The FCC designed the auction eligibility rules to discourage hiding in the grass. To maintain eligibility in the first stage of the auction (which the FCC ended in round 20), each bidder needed to remain "active," by holding or raising the prevailing bid, on at least one-third of the bandwidth it ultimately sought to buy. ${ }^{99}$ In the second stage (which the FCC ended in round 73), each bidder needed to remain active on two-thirds of the bandwidth it ultimately sought to buy. ${ }^{100}$ By round 12 , nearly all of the excess non-designated bidder eligibility came from

\footnotetext{
${ }^{96}$ Only four non-designated firms, AirTouch, Americtech, Radiofone, and Westlink, showed any regional demand. Our \$45 million estimate already takes into account the pressure that Radiofone and Westlink exerted on the bidding by setting the pre-crossover designated bidding benchmark at the prevailing prices when these firms dropped out of the bidding. And because the demand of AirTouch and Ameritech was ultimately satisfied, the regional demand of these bidders was not the excess demand that caused the last $\$ 45$ million in bidding.

${ }_{97}^{97}$ Even if limited capital constrained prices in the nationwide auction, bidders in the regional auction would not have used their increased liquidity unless necessary. Our previous analysis of regional bidding indicates that prices were not increased by competition among large, liquid non-designated bidders in the last rounds of the auction; instead, PCSD's subsidized crossover bidding drove prices up.

${ }^{98}$ There is some evidence that GTE employed this strategy in the initial rounds of the broadband auction. See MILGROM supra note 46, at 47 .

${ }^{99}$ See note 46 supra.

${ }^{100} I d$.
} 
ultimate license winners. ${ }^{101}$ These eligible non-designated bidders represent the only potential sources of unobserved excess demand.

The observed bidding behavior of these eligible non-designated bidders, however, was not consistent with a hiding in the grass strategy. A snake holds back in early rounds, intending to increase demand in later rounds. But no bidder increased its demand for licenses after round $12 .{ }^{102}$ To the contrary, as prices rose, bidders reduced demand. ${ }^{103}$ For example, MobileMedia began by demanding three nationwide aggregations, and PageMart demanded two. After round 1, MobileMedia reduced its demand to two nationwide aggregations, and after round 6 , further reduced it to one band. By round 7, PageMart had also cut its demand to a single nationwide aggregation. ${ }^{104}$

That individual nationwide bidders controlled three of the four non-setaside frequency blocks by round 12 makes us particularly confident that hiding in the grass would not have been a rational strategy. As discussed below, ${ }^{105}$ bidders that hold the prevailing bid for a national aggregation are willing to pay a premium in order to retain the aggregation. Breaking up a bidder's national aggregation can expose the bidder to significant losses if it must buy a subset of the regional licenses; thus, any snake that waited until later rounds to show its demand would confront an opponent whose fear of suffering significant losses would bolster its willingness to compete. Hiding in the grass appears irrational as it creates more hardened national rivals that need to defend their aggregations. ${ }^{106}$

Not only would it be unprofitable to hide in the grass in hopes of outbidding an entrenched nationwide bidder, but the strategy would also unlikely provide an advantage against a rival bidding on only a single license. The strategic rationale for hiding in the grass, that the competitor may commit too much of its budget to another license, does not apply to single license bidders. Excluding nationwide and single license bidders as potential targets of a hiding in the grass strategy eliminates virtually all non-designated bidders. While it is impossible to prove that in the absence of crossover bidding additional non-designated demand would not have surfaced, the observed bidding behavior, as well as partial aggregation risk, strongly discounts this hypothesis as a plausible reason to question our excess demand benchmark.

\section{The designated bidders would have bid anyway.}

Our excess demand benchmark might also fail if designated bidders (or their passive non-designated partners) still would have raised prices without affirmative action. Our $\$ 45$ million estimate implicitly assumes that, without affirmative action, no bidder would have increased the price beyond the point at which the excess nondesignated bidders dropped out. But if the designated bidders or their passive non-designated partners would have bid up the price even without affirmative action, then all price increases could not be attributed to the presence of affirmative action.

We think it unlikely that either the designated bidders or their passive partwould have enhanced competition in the absence of affirmative action. None of the designated bidders or their partners appears to have had the resources to bid successfully without affirmative action-indeed, none of these firms was a serious contender in the earlier nationwide auction. The installment payment subsidy was especially important in inducing the designated bids. Without government financing, designated bidders would have needed five times as much liquid capital to pay for the licenses.

Even if designated bidders would have been willing to pay the same present value in the absence of affirmative action, the government revenue would still have been much less-because of the interest rate subsidy increasing the nominal designated bids and forcing non-designated firms to pay 16 percent more. Table 3 estimated that in present value terms designated entities paid $\$ 76.7$ and $\$ 44.8$ million respectively for the setaside 50/50 and 50/12 blocks. ${ }^{107}$ Even if we made an assumption more unfavorable to our thesis-that in the

\footnotetext{
${ }^{101}$ The only other bidders who remained eligible were Constant, Radiofone, and Westlink. See Table 2 supra.

102 The only exception is PageMart's bidding for multiple 50/12 licenses, as in rounds 72 and 74 . This behavior, however, was not hiding in the grass: Before round 73, PageMart tested multiple bidders in a single round, which was consistent with its behavior in the nationwide auction. After round 73, Stage 3's heightened activity rules required multiple license bidding-PageMart needed to bid on two $50 / 12$ licenses to retain the option of later bidding on a single 50/50 license.

${ }^{103}$ The early rounds of the auction were characterized by aggressive, jump bidding to stake out large claims. See MILGROM, supra note 46 , at 32

${ }^{104}$ These reductions in demand are consistent with the behavior of these firms in the nationwide auction, where no bidder increased demand after the first few rounds of bidding. Even if the crossover designated bidding ultimately outstripped the amounts that possible snake bidders were willing to pay, snake bidders should have emerged before the bids went above their reservation price, hoping to bid just as the designated bidders were dropping out. However, these interim increases in non-designated demand never materialized.

${ }^{105}$ See notes 112-116 infra and accompanying text.

${ }^{106}$ Likewise, national aggregate bidders become more vulnerable to retaliation as the amounts at stake increase, and they therefore are much more likely to test the waters by revealing their increased demand before they commit to defending their aggregations. The high cost of partial aggregation suggests that the national aggregate bidders would not have chosen to hide in the grass and risk retaliation.

${ }^{107}$ See Table 3 supra.
} 
absence of affirmative action, there would be sufficient designated demand to buy all six blocks at these priceswe still find that affirmative action would have increased the auction price by more than $\$ 38$ million. ${ }^{108}$ But given our strong belief that designated bidders would not have been willing to bid as much (or at all) in the absence of the 80 percent government financing, ${ }^{109}$ we are also confident in rejecting this criticism of our excess demand benchmark.

\section{Affirmative action might have chilled non-designated bidder participation.}

Finally, it is possible that affirmative action deterred some non-designated bidders from participating in the regional auction. Given the effective set-aside of Blocks 2 and 6, some non-designated bidders may have calculated that it was not worth the fixed costs of preparing for an auction-including the substantial expense of amassing a war chest to pay quickly for any purchased licenses. This theory would undercut our excess demand benchmark, because, in the absence of affirmative action, these additional non-designated bidders may have driven up the prices beyond the amounts at which the participating non-designated bidders dropped out.

This theory seriously qualifies our reliance on the excess demand methodology. However, we note that there were no conspicuous "no shows' at the regional auction. All of the nationwide bidders that could legally purchase additional licenses made substantial up front payments and then actively bid in the regional auction. ${ }^{110}$ This is not surprising: The nationwide auction bidders would have incurred most of the fixed costs necessary to participate in the regional auction. Thus, while we cannot guarantee that without affirmative action other nondesignated bidders would not have entered to provide additional competition, no direct evidence of deterred participation exists. ${ }^{111}$

\section{Strategic Perversities: Bidding Above Atomistic Reservation Prices}

The preceding analysis assumed that bidders' reservation prices for particular licenses were independent of who won other licenses. In this section, we show how simultaneously auctioning multiple licenses might lead bidders to pay more for a license than they would pay if the license were offered in isolation.

\section{Risk of partial aggregation.}

In an auction for regional licenses, a bidder that values a national aggregation more than its constituent parts risks winning a subset of regional licenses. Because the cost of an incomplete aggregation may be greater than its synergistic reservation price, an auction participant may be willing to place a total bid that exceeds its reservation price for the aggregation.

This perverse overbidding is analogous to the bidding behavior observed in simple classroom demonstrations of a "both pay" auction in which the professor offers to auction a prize of $\$ 10$ to two students. The prize goes to the student who bids the most, but the game also requires each bidder to pay the amount of her last bid. Requiring both the winner and the loser to pay often induces each of the students to bid more than $\$ \$ 10$ - because a bidder about to lose the auction with a $\$ 9$ bid would prefer to win with an $\$ 11$ bid (and thereby lose $\$ 1$ instead of $\$ 9$ ). ${ }^{112}$ The crucial feature of this game is that making the loser pay can induce both bidders to bid above their reservation prices-this is the core aspect of all "war of attrition" or "escalation" games. ${ }^{113}$

To see how the risk of partial aggregation induces similar overbidding as a "both pay" game, consider an "incumbent" bidder that values owning a national aggregation of five licenses at $\$ 100$ ( $\$ 20$ per license) but values owning four of the five at only $\$ 40$ ( $\$ 10$ per license). If it held high bids of $\$ 15$ on all five ( $\$ 75$ total) and

${ }^{108}$ If, in the absence of affirmative action, designated demand pushed up the price that the designated winners were willing to pay with affirmative action, then the six blocks would have sold for $\$ 332.4$ million $((76.6 \times 2)+(44.8 \times 4))$ which is $\$ 38.5$ million less than the auction with affirmative action produced.

${ }^{109}$ See text accompanying notes 59-61.

${ }^{110}$ Pagenet could not purchase additional licenses because the FCC prohibits firms from owning more than three licenses.

${ }^{111}$ While the text has focused primarily on the possibility that affirmative action might have deterred non-designated bidders from incurring fixed costs of participation, it is also possible that affirmative action might have deterred non-designated bidders from incurring nonfixed costs, such as investigating the value of licenses (as much as they would have in the absence of affirmative action). Spending less on such investigations might then exacerbate the "winner's curse' (to the extent that the auction had a common value element, see note 24 supra) and consequently reduce the reservation prices of even those non-designated bidders that participated in the auction. See Cramton, supra note 44, at 279-82. While reducing the quantity of licenses available would seem to induce less investigation on the margin, the strategic interaction of bidders is not so straightforward. Game-theorists have shown that reducing the quantity of items being auctioned may, for a variety of subtle reasons, induce greater bidder investigation. See Cramton, supra note 44, at 24 . Because it is difficult to even "sign" the effect of affirmative action on how much bidders will investigate and because many of the investigations would have already been incurred in preparation for the nationwide auction, we believe this possibility is of secondary importance.

112 Barry O'Neill, International Escalation and the Dollar Auction, 30 J. Conflict Resolution 33 (1986); Martin Shubik, The Dollar Auction Came: A Paradox in Noncooperative Behavior and Escalation, 15 J. CONFLICT RESOLUTION 109 (1971).

${ }^{113}$ See, e.g., John G. Riley, Strong Evolutionary Equilibrium and the War of Attrition, 82 J. THEORETICAL BIOLOGY 383, 383-85 (1979). 
then an "attacker" bid up the price of individual licenses, a rational incumbent would worry mat if it were to lose one license, it would be stuck paying $\$ 60$ (at $\$ 15$ per license) for the other four licenses that it valued at only $\$ 40$. To avoid losing the fifth license, the incumbent would be willing to spend up to $\$ 120$ to win all five licenses. ${ }^{114}$ This might mean, for example, that if the bidder thought it could win all five for $\$ 23$ each, it would prefer bidding above its reservation price rather than winning four for $\$ 15$ each. ${ }^{115}$

The risk of partial aggregation may induce a firm to bid more than its reservation price, including the synergistic value, for a national aggregation of licenses. As in the "both pay" auction, the prospect of a negative payoff leads to higher bidding. The cost of defending their national aggregations may explain why PageMart, MobileMedia, and Advanced Wireless were willing to pay so much more after PCSD began its crossover bidding: The PCSD crossover might have surprised them and disrupted PageMart's national aggregation. ${ }^{116}$ Yet the possibility that partial aggregation exposure induced higher bidding does not undermine our positive thesis. The bidding pattern shows clearly that PCSD's crossover bidding started the chain of events that disrupted PageMart, Multimedia, and Advanced Wireless' national aggregations. Thus, even under this theory, affirmative action was a but-for cause of these higher prices (indeed partial aggregation risks enhanced the effect of designated bidder crossovers).

\section{Raising rivals' costs and predatory strategies.}

Not only does the risk of partial aggregation affect incumbents' bidding behavior, it may also have secondary effects on other auction participants. Anticipating that aggregate bidders will pay inflated prices to avoid being stuck with partial aggregations, firms may strategically choose to bid up the price of a rival's individual license in order to weaken their rivals' market positions (e.g., requiring the rival to charge higher use-fees to cover its interest payments).

While such behavior is theoretically possible, it is probably not rational for a firm to engage in this strategy because the risk of actually buying one of the rival's regional licenses, should the rival drop out of the bidding, likely outweighs any advantage. Additionally, money spent on licenses is sunk and therefore should not affect a rival's subsequent pricing decisions. ${ }^{117}$ Finally, engaging in this strategy may induce the rival to retaliate, especially if the initial bidder is itself trying to form a national aggregation.

As an alternative, a bidder may engage in an even more extreme "predatory" strategy. Whereas the goal of raising rivals' costs is just to make them pay more for their licenses, predation seeks to stop the rival from forming a national aggregation. Breaking up a rival's national aggregation might increase the marginal cost of providing certain nationwide paging services (and thus satisfy Salop's marginality requirement). But given bidders' aforementioned willingness to defend their national aggregation 'turf,' we doubt that reducing the number of national competitors from nine to eight would be worth the amount of money needed to outbid an entrenched firm. ${ }^{118}$

Nonetheless, there is some evidence that, in shifting its demand from 50/50 licenses to the 50/12 licenses after PCSD's crossover, PageMart targeted MobileMedia and Advanced Wireless' national aggregations even though AirTouch's licenses were then cheaper. ${ }^{119}$ While it is possible to interpret these episodes as evidence of either a "raising rivals" costs" or a "predatory" strategy, we think it more likely that PageMart was engaged in a "temporizing" strategy in which PageMart attempted to retain eligibility by remaining active on the 50/12 licenses so that it could later return to bid against PCSD for the Block 1 national aggregation. ${ }^{120}$ Thus, PageMart bid against the national aggregators despite the higher prevailing bids in these markets, because PageMart had greater confidence that these bidders would defend their national aggregation and ultimately outbid PageMart.

\footnotetext{
${ }^{114}$ If the attacker were bidding only on a particular license, the incumbent might bid up to $\$ 60$ to retain the license-meaning that it would pay $\$ 60$ for four licenses and $\$ 60$ for the attacked license. However, an attacker will often switch its bidding among the five licenses, increasing the price of each.

${ }^{115}$ If the incumbent miscalculates and later finds that $\$ 23$ per license is not sufficient to win all five, her predicament deepens. Having high bids of $\$ 23$ on four licenses means that the incumbent now stands to lose $\$ 52(\$ 40$ - $\$ 92)$, which means she should now be willing to bid up to a total of $\$ 152$ to win all five, or more than $\$ 30$ per license. Just as in the simple "both pay" auction and other "war of attrition games," a bidder's belief that she can win at an intermediate value determines her willingness to continue.

${ }^{116}$ See notes 119-121 infra and accompanying text for a discussion of PageMart's motivation for bidding against MobileMedia and Advanced Wireless when Frequency Block 5 (50/12) licenses were cheaper.

${ }^{117}$ See, e.g., Thomas G. Krattenmaker \& Steven C. Salop, Anticompetitive \&elusion: Raising Rivals' Costs to Achieve Power over Price, 96 YALE L.J. 209 (1986) (emphasizing that only strategies that raise a rival's marginal costs are likely to weaken its ability to compete).

${ }^{118}$ The nationwide auction produced 10 nationwide competitors and the regional auction added four more. See Table 3 supra; note 65 supra. The number of nationwide competitors may increase further when the FCC auctions subsequent narrowband blocks.

119 AirTouch also bid against MobileMedia and Advanced Wireless but only when the prevailing bids on Blocks 3 and 4 were cheaper than AirTouch's Block 5 bid. Rather than engaging in predation, AirTouch was arbitraging a price difference.

120 This term and this interpretation of PageMart's strategy were developed by Milgrom. See MiLgrom, supra note 46, at 31-34 (describing the Lidding strategy of PageMart).
} 
This provides a nonpredatory explanation for why PageMart might have been willing to bid on Blocks 3 and 4 when AirTouch's comparable Block 5 licenses were cheaper. ${ }^{121}$

Regardless of PageMart's motivation, it is clear that PageMart's 50/12 bidding was caused by PCSD's crossover. PageMart showed no interest in the 50/ 12 licenses until PCSD repeatedly bid up the price of the Block 1 (50/50) licenses. Moreover, PCSD's disruption of the Block 1 licenses both gave PageMart an excuse for bidding on the 50/12 licenses and made PageMart less susceptible to retaliation from Advanced Wireless and Mobile Media. ${ }^{122}$

\section{Reduced retail competition.}

Because firms were bidding for the right to provide paging services in competition with other license winners, auction rules that affected the identity of the ultimate retail competitors, such as affirmative action, also might have affected how much a firm was willing to bid. Specifically, if affirmative action reduced the expected competitiveness in the paging services market, then non-designated bidders might have been willing to pay more to enter the market. ${ }^{123}$ If non-designated bidders perceived that their designated competitors would have higher marginal costs or limited capacity, they might be willing to bid more for a license because they would expect to earn higher oligopolistic profits in the paging market.

We do not, however, believe that this hypothesis provides a plausible explanation for the narrowband bidding. In most regions, designated bidders hold only two of seventeen narrowband licenses (and there are thirteen nationwide non-designated bidder aggregations). Even if the designated bidders were less effective competitors, ${ }^{124}$ the reduction from seventeen to fifteen strong competitors should not substantially affect pricing.

Reduced competition also does not explain why designated bidders and their passive non-designated partners were willing to pay such substantial sums for licenses, if they expected difficulty succeeding in the subsequent market-place. ${ }^{125}$ We have nonetheless highlighted this possibility to underscore the point that producing more government revenue is not the same as allocating licenses to the most efficient users. ${ }^{126}$

This section has shown how affirmative action in the FCC's regional narrowband auction increased government revenues. While game-theorists have long understood as a matter of theory that subsidizing weaker bidders can enhance a seller's expected payoff, we have presented the first empirical demonstration that subsidies can increase revenue. ${ }^{127}$ We do not claim that the FCC intended this effect. Nor do we claim that affirmative action increased revenues in other FCC auctions where designated bidder subsidies were smaller, less comprehensively designed, or nonexistent. Indeed, designated subsidies might have stimulated bidding

${ }^{121}$ Indeed, there is some evidence that at times PageMart might have been trying to win one or more of the 50/12 licenses. For example, in round 72, PageMart entered jump bids of \$14 million in the West region on all three 50/12 frequency blocks (Blocks 3, 4, and 5). PageMart's message appeared to be that it preferred a 50/12 in the West at $\$ 14$ million to a 50/50 at nearly $\$ 21$ million. PageMart was challenging each of the non-designated $50 / 12$ bidders in the West to top $\$ 14$ million or leave it to PageMart. See ftp://ftp.fcc.gov/pub/Auctions/PCS/Narrowband/Regional/Round-072/s3-72.txt.

${ }^{122}$ Retaliation would be harder to accomplish because PageMart was no longer defending a national aggregation of the 50/50 licenses. PageMart's bidding on Blocks 3 and 4, when Block 5 licenses were cheaper, led to final bids on Blocks 3 and 4 that were $\$ 4.1$ million higher than the final Block 5 bids. Even if PageMart were not a predator, MobileMedia and Advanced Wireless would have had to pay at least what Block 5 winners paid because the Block 5 winners (AirTouch, InstaCheck, and Ameritech) switched whenever there was an arbitrage opportunity. Final bids for Blocks 3 and 4 each totaled approximately $\$ 53.6$ million, and the final bid for Block 5 was $\$ 49.6$, which included the \$2.1 million PageMart penalty. See note 63 supra and accompanying text. Thus, even if the instances of PageMart's bidding on the more expensive 50/12 licenses were not caused by affirmative action, "predation" would only reduce our $\$ 45$ million estimate for the aggregate effect of affirmative action by a few million.

${ }^{123}$ At the extreme, if firms expected that without affirmative action, non-designated bidders would win all of the licenses and compete the price of paging services down to its marginal cost, then firms would only have been willing to bid very little.

${ }^{124}$ We are skeptical that designated bidders will prove to be less efficient. First, the "build out" costs of exploiting a narrowband license are small (approximately $\$ 2.5$ million) compared with the cost of the licenses. Third Report \& Order, supra note 20 , at 2969 n.40. Second, the designated bidders, together with the* partners, have sufficient capital and expertise to bring PCS paging services to market.

${ }^{125}$ If there were fewer licenses for sale, however, it would be possible to construct an example in which a designated bidder would be willing to pay a substantial sum for a license: For example, if the FCC sold only two licenses, setting one aside for a designated bidder, then a designated bidder that could commit to limiting its capacity might expect to earn supracompetitive profits. The non-designated bidder would then find it profitable to charge a supracompetitive price and might not find it worthwhile to drive the less efficient designated bidder from the market. See Judith R. Gelman \& Steven C. Salop, Judo Economics: Capacity Limitation and Coupon Competition, 14 Bell J. ECON. 315 (1983) (outlining strategies for smaller firms to effectively compete with larger firms).

${ }^{126}$ Game-theorists analyzing the "success" of the FCC auctions may tend to equate the highest willingness to pay with the most efficient user. Regulators, however, may worry that the firms that can most easily collude would be willing to bid the most. Also, large bidders have a strong incentive to reduce demand to keep auction prices low. See Lawrence M. Asubel \& Peter C. Cramton, Demand Reduction and Inefficiency in Multi-Unit Auctions, (Univ. of Md. Working Paper, 1995). Hence, small bidders (like InstaCheck) may inefficiently win licenses when the large bidders (like AirTouch) have higher valuations.

127 Controlled experiments have shown similar results. Andrew Schotter \& Keith Weigelt, Asymmetric Tournaments, Equal Opportunity Laws, and Affirmative Action: Some Experimental Results, 107 Q.J. ECON. 511 (1992) (finding that affirmative action may lead to increased employee effort and employer revenue); see also Allan Corns \& Andrew Schotter, Can Affirmative Action be Cost Effective? An Experimental Examination of Price-Preferences, (N.Y. Univ. Working Paper, 1996). 
competition in other FCC auctions. For example, in the initial broadband auction, which did not include any designated prefferences, ${ }^{128}$ competition for several licenses was relatively weak. While a few small bidders helped drive up prices, subsidized designated bidding might have further increased competition and auction revenues. ${ }^{129}$

\section{APPLICATIONS TO GOVERNMENT PROCUREMENT AND PRIVATE EMPLOYMENT}

FCC auctions are not the only arena in which affirmative action subsidies might enhance competition. This Part illustrates how an analogous effect could reduce government procurement costs or increase private employer profits. As we emphasized in our discussion of affirmative action's effect on auction revenue, ${ }^{130}$ affirmative action is likely to increase competition only if:

(1) absent affirmative action, there would be insufficient bidding competition; and

(2) the decisionmaker is able to estimate the expected difference between the reservation prices of preferred and nonpreferred bidders.

While these conditions would not apply to most employment and procurement settings, the strength of the FCC data suggests that affirmative action could enhance competition in a limited set of circumstances.

\section{A. Government Procurement}

While our finding that affirmative action enhanced bidding competition in the FCC's sale of telecommunication licenses is itself significant, affirmative action may also enhance bidding competition when the government is a buyer. Inducing bidders to sell goods and services to the government at lower prices could affect a significant portion of the economy: Procurement by federal, state, and local governments accounts for "about 10 percent of the GNP or approximately $\$ 450$ billion per year. ${ }^{131}$

There is ample evidence that the current procurement process is not always sufficient to guarantee the government a good price. Even beyond the hype of anecdotal $\$ 450$ dollar hammers ${ }^{132}$ relatively few firms bid for major contracts. For example, Steven Kelman's detailed case studies of computer procurement found an average of only 4.2 bidders per contract. ${ }^{133}$ Furthermore, procurement officers "often demonstrate a preference for a familiar product or an incumbent firm. This kind of firm-specific favoritism is well known in procurement circles and has led to such expressions as, "No one was ever fired for buying from IBM." ${ }^{134}$ Favoritism for

\footnotetext{
${ }^{128}$ Because of a concern that auctions with set-asides might be delayed by suits challenging the constitutionality of race- and genderbased preferences, the FCC limited designated preferences to a fixed set of licenses and conducted separate auctions for broadband licenses with and without designated preferences, Separating the auctions (and thereby "quarantining" the designated licenses), allowed the nondesignated auctions to take place without delay.

As feared, the first broadband auction with designated preferences was stalled in the courts. On March 15, 1995, the U.S. Court of Appeals for the District of Columbia stayed the auction until it could hear the case brought by Telephone Electronics Corporation ("TEC"), a rural telephone company. TEC claimed that it was unfairly excluded from the auction and questioned the constitutionality of bidder preferences for women and minorities. See Edmund L. Andrews, Court Stalls FCC Program for Women and Minorities, N.Y.TIMES, Mar. 16, 1995, at A22. On April 18, TEC unexpectedly withdrew its lawsuit in a settlement with the FCC. See Gautan Naik, Firm Plans End to Challenge of PCS Auction, WALL ST. J., Apr. 19, 1995, at A3. The auction, which was scheduled to begin in June 1995, was postponed until early August, and then again when the June 12 Supreme Court decision in Adarand Constr. v. Pena, 115 S. Ct. 2097 (1995) made it likely that the race and sex preferences would not survive constitutional challenge. The FCC modified the rules to give all small businesses, regardless of the race or sex of its owners, the same $25 \%$ price preference and attractive payment terms previously available only to womenor minority-controlled firms. The auction was rescheduled for August 29. However, it was postponed yet again when the D.C. Circuit stayed the auction in response to a suit filed by Omnipoint, a New York provider that claimed the new rules would allow large companies to dominate the auction by making it too easy for small companies to serve as fronts for large ones. See Edmund L. Andrews, FCC is Ordered to Delay an Auction for Wireless Licenses, N.Y. TIMES, July 28, 1995, at D4. The D.C. Circuit again lifted the stay, and the auction was rescheduled for December 11. The Sixth Circuit then granted another stay, but the Supreme Court lifted that stay on October 30. FCC v. Radiofone, Inc., 116 S. Ct. 373 (1995); FCC v. Radiofone, Inc., 116 S. Ct. 283 (Stevens, Circuit Justice 1995). The auction finally began on December 18, 1995.

${ }^{129}$ The bidders McCaw and American Portable were especially important. See Cramton, supra note 2, at 15-24 (describing the bidding in the broadband auction). Although 62 bidders applied to bid, only 30 followed through with the required upfront payment. Id. at 17. Clearly, a number of potential bidders were unable to participate because of a lack of capital.

${ }^{130}$ See notes 19-25, 34-41 supra and accompanying texts. (1990)).

${ }^{131}$ Marshall, Meurer \& Richard, supra note 35, at 3 n I (citing Steven Kelman, Procurement and Public Management 2

132 Jerry Mashaw, The Fear of Discretion in Government Procurement, 8 YALE J. ON REG. 511, 511 (1991) (discussing media distortions in coverage of government procurements).

${ }^{133}$ See Marshall, Meurer \& Richard, supra note 35, at 8 n.23 (citing KelmAN, supra note 131, at 109-83).

${ }^{134}$ Id. at 14 n.49; see also Jean-Jacques Laffont \& Jean Tirole, Auction Design and Favoritism, 9 INT'L J. INDUS. ORG. 9 (1991) (discussing effects of auction favoritism on seller's ability to maximize profits).
} 
incumbent firms reduces bidding competition by entrenching the market power of either one or a small number of firms.

Affirmative action can enhance bidding competition and reduce the government's cost of procurement in the same ways that it increased the government's revenue from selling narrowband licenses. The nonpreferred private firms competing to sell the government goods and services are likely to bid more aggressively (i.e., offer lower prices) both because they might have to compete against subsidized bidders and because they might have to compete for fewer contracts.

While our earlier examples demonstrated the revenue-enhancing effect of affirmative action in multipleround, open-bid auctions, affirmative action in single-round, sealed-bid auctions, commonly used in government procurement, can produce the same results. ${ }^{135}$ A private bidder who knows it must compete with a large number of subsidized bidders may reduce the markup in its sealed bid to increase its chances of winning the contract. Giving traditionally disadvantaged groups bidding subsidies may be especially effective in destabilizing tacit collusion for the very reason that bidders from different social networks may have more difficulty coordinating behavior.

Set-asides may also create lower overall procurement costs because the reduced quantity of contracts available to nonpreferred firms can induce them to bid more aggressively. For example, if four incumbent construction firms were bidding to build four different playgrounds, they might be able to coordinate their bidding (either tacitly or explicitly) to divide the contracts among themselves. Setting aside one of the bidding contracts for traditionally disadvantaged, nonincumbent firms may enhance intragroup competition, as the four incumbents must now compete for just three contracts. Any incumbent that believes it may end up empty-handed is likely to reduce the markup in its sealed bid. While the government may pay more on contracts set aside for traditionally disadvantaged bidders, reduced costs for non-set-aside contracts can lower overall procurement costs.

Failing to recognize how affirmative action can be used to enhance procurement competition grossly overstates the cost of affirmative action subsidies. For example, nonpartisan state legislative analysts estimate the California Department of General Services spent an additional \$9.9 million last year by rejecting low bids from firms that failed to comply with affirmative action requirements. Unfortunately, these estimates ignore how affirmative action may have driven down the low bids that were used as the benchmark. ${ }^{136}$ Without the enhanced bidding competition created by affirmative action, these low bids and the low bids on other bidding contracts may have been substantially higher. While we do not have access to sufficient data to reliably claim that affirmative action reduced California's procurement costs, the procompetitive effects of subsidizing weak bidders (and the evidence from the FCC's regional narrowband auction itself) suggest that affirmative action is much less costly than appears from simply comparing the low bids to the winning bids of traditionally disadvantaged firms.

There is even a sense in which affirmative action promotes the "full and open competition" mandated by the Competition in Contracting Act of $1984 .{ }^{137}$ The government procurement process seeks to balance three competing goals of "equity (fair access to competing bidders), integrity (reduction in opportunities for corruption) and economy, (obtaining goods or services required at the lowest possible price)." 138 Although the main thrust of our argument has concerned economy, affirmative action may also increase fairness and integrity. When affirmative action increases auction competition, it inevitably diminishes firms' opportunities to bilk the government. The privilege of participating in a noncompetitive auction could be recharacterized as unfair access to the public fisc. And affirmative action may promote fairness by redressing past and present instances of either private or governmental discrimination. To the extent well-organized incumbents are more likely to capture or corrupt the purchasing process, ${ }^{139}$ affirmative action subsidies counteract both possibilities by forcing favored incumbents to bid closer to their reservation prices.

Moreover, the enhanced bidding competition induced by affirmative action need not reduce efficiency in government procurement. While selling to higher cost producers decreases productive efficiency (as in the FCC auctions), creating lower overall prices may increase allocative efficiency by inducing the government to make more efficient choices about the quantity and mix of its purchases. Absent the bidding competition affirmative action fosters, the government may face inflated procurement prices which distort its choice of inputs. In

\footnotetext{
135 See generally Kelman, supra note 131 (describing common procurement methods).

${ }^{136}$ Indeed, a strategic bidder who knows that it is not in compliance with state affirmative action requirements might have an incentive to purposefully enter a low-ball bid to exacerbate the perceived cost of affirmative action.

${ }^{137} 10$ U.S.C. $§ 2304$ (1994). The Competition in Contracting Act of 1984 attempted to discourage sole-source procurement partly by raising the status of procurement by competitive proposals. Mashaw, supra note 132, at 513.

${ }_{138}$ Mashaw, supra note 132, at 512.

139 See generally IAn Ayres \& John Braithwaite, Responsive Regulation: Transcending the Deregulation Debate 54-100 (1992) (discussing factors conducive to regulatory capture).
} 
efficiency terms, the increase in allocative efficiency may outweigh or at least mitigate the decrease in productive efficiency caused by selling to disadvantaged firms with higher production costs. ${ }^{140}$

Although the preceding analysis suggests that the procurement context satisfies the first precondition (the revenue-enhancement effect), the government still faces a substantial information problem in calculating the size of the affirmative action subsidy. Even if the government is confident that disadvantaged contractors are likely to be weaker bidders, the government would still need to estimate the expected difference in reservation prices to know how much of a subsidy or set-aside would lower costs. This is not a straightforward calculation, but the government does makes just this kind of calculation when it subsidizes small businesses. For example, the Department of Defense sometimes reimburses small bidders for certain bidding costs if it anticipates greater competition will lower the government's price. ${ }^{141}$ Even if the government does not have the requisite data to ensure that affirmative action actually decreases procurement costs, the government may have sufficient information (e.g., data concerning the effects of past bidding) to be confident that affirmative action is less costly than the direct cost of the subsidy.

\section{B. Private Employment}

To explore the limits of our analysis, this section considers whether affirmative action could induce workers to "bid" more aggressively for their jobs. Although employees do not literally hid for their jobs, their decisions over how hard to work or what level of pay to accept might be analogized to an auction bid. Workers may commit to work harder or for less money if they face subsidized competition from preferred job applicants or have to compete for fewer jobs because some are set aside for a preferred class.

While our goal for the moment is to assess whether as a positive matter private employers would have a profit motive for engaging in this type of affirmative action, we emphasize that the translation of our theory from firmbased preferences to individual-based preferences raises two troubling normative problems. First, the premise that women or minority workers have lower expected productivity is a more invidious stereotype than the FCC's assumption concerning designated bidders' ability to compete. Even if the choice to subsidize disenfranchised groups were based on the disadvantages to which the individuals had been subjected, this profit motive for affirmative action lacks the moral coherence of standard diversity theory, which presumes not that traditionally disadvantaged workers are less productive, but that they bring different life experiences to their jobs, which synergistically enhance corporate decisionmaking. ${ }^{142}$ Second, the goal of extracting additional surplus from white and/or male workers is more problematic than extracting additional surplus from non-designated firms. ${ }^{143}$ Nondesignated bidders have no right to make supracompetitive profits from our nation's finite radio spectrum, but workers have a normative claim to some of the surplus from their employment. The problem is that employers would use affirmative action to extract additional surplus from non preferred workers.

We return to these normative issues in the final section, but even at a positive level, we believe that, in the labor markets, the two preconditions for affirmative action to enhance competition rarely both obtain. Employers do not need to resort to affirmative action to extract surplus from white or male employees because competition among these employees is sufficient to drive the wage to the marginal product. Due to the persistent unemployment in the United States, the number of job applicants usually far exceeds the number of openings. Under such conditions, voluntary affirmative action would not be necessary for employers to gain bargaining power: Affirmative action is most likely to be able to spur additional competition only if there are relatively few bidders compared to the number of items being auctioned.

140 This enhancement in allocative efficiency would not apply to the government's sale of FCC licenses unless the government's choice of what or how much to sell were influenced by artificially deflated revenues.

The importance of allocative efficiency is at the core of Henry Manne's justification for legalizing insider trading: If insider trading drives stock prices more quickly toward their true value, better investment and consumptive choices might follow legalizing its exchange. HENRY G. MANNE, INSIDER TRADEING AND THE STOCK MARKET (1966).

${ }^{141}$ Jerome S. Gabig \& Richard C. Bean, A Primer on Federal Information Systems Acquisitions: Part Two of a Two-Part Article, 17 Pub CONT. L.J. 553, 580-81 (1987) (discussing Department of Defense proposals to subsidize benchmarking costs for small information systems firms).

${ }^{142}$ See, e.g., Taylor Cox, Jr., The Multicultural Organization, 5 ACAD. MGMT. EXEC. 34 (1991) (contending the diversity enhances decisionmaking, creativity, and marketing to foreign communities); Duncan Kennedy, A Cultural Pluralist Case for Affirmative Action in Legal Academia, 1990 DUKE L.J. 705 (arguing that affirmative action would improve the quality and social value of legal scholarship).

${ }^{143}$ In a sense the employer would be using affirmative action to induce a "rat race." See George Akerlof, The Economics of Caste and of the Rat Race and Other Woeful Tales, 90 Q.J. ECON. 599, 60305 (1976). The rat race effect results from workers' increasing their efforts to distinguish themselves from other coworkers without considering that their extra efforts would inspire others to work harder. The rat race effect might intensify where workers with higher expected productivity had to work even harder to exceed the subsidized output of workers with lower expected productivity.

The rat race effect underscores how affirmative action's possible profit motive will usually reduce social efficiency. While reducing workers' market power may lead to more efficient use of labor, see note 140 supra and accompanying text, it is just as likely that employees' disutility of work will exceed employers' enhanced profitability. 
Nonetheless, we see a small possibility that employers could benefit from using affirmative action to enhance their bargaining power when, because of private information and/or contracting costs, employers are unable to extract all of the gains from trade. ${ }^{144} \mathrm{~A}$ recent article by Andrew Schotter and Keith Weigelt experimentally tested whether affirmative action subsidies could spur employees to work harder. ${ }^{145}$ These authors found that overall effort of their subjects increased when weak "employees" were favored. While there is only indirect empirical evidence that affirmative action enhances productivity, ${ }^{146}$ our enhanced-competition theory may provide a causal explanation for two of the most important changes during the last decade in entry level hiring for law teaching-(1) an increase in the perceived amount of affirmative action and (2) an increase in the number of publications candidates must write before application.

We remain skeptical, however, that employers would subsidize disadvantaged applicants solely to maximize profits. Even if affirmative action subsidies or set-asides could profitably enhance employers' bargaining power, few employers have sufficient information to risk subsidizing workers with lower expected productivity when profit-maximization is their sole motivation. ${ }^{147}$ However, when employers are motivated by other factors to offer affirmative action subsidies, our overarching conclusion still pertains: Private employment subsidies may not be nearly as costly as commonly assumed if they enhance the employer's terms of trade with nonpreferred employees.

\section{IV.LEGAL IMPLICATIONS}

The central thesis of this article has been positive rather than nonnative: Affirmative action can (and in the FCC auction did) increase government revenues by enhancing bidding competition. But at some level this fact is insignificant unless it informs normative legal issues. Accordingly, this section addresses the normative relevance of the revenue-enhancing effect.

\section{A. Public Affirmative Action}

An expected increase in government revenue or decrease in government procurement costs is an inadequate constitutional rationale for race- or gender-conscious subsidies. But, in cases where there are independent constitutional justifications, the simple fact that affirmative action subsidies may not be as costly as is commonly thought may help demonstrate that affirmative action is cost-justified.

\section{Revenue enhancement is constitutionally insufficient.}

After Croson ${ }^{148}$ and Adarand, ${ }^{149}$ to withstand an equal protection attack, a racial subsidy must be "narrowly tailored" to further a "compelling government interest." ${ }^{150}$ Reducing the federal government's budget deficit is

\footnotetext{
${ }^{144}$ Most importantly, employers often receive only a noisy signal about the expected productivity of a particular applicant. The heterogeneity in expected productivity reduces the competitive pressure that employees with the strongest resumes face from other applicants with less scintillating resumes. Because applicants may know more about their prospective productivity than employers, employers cannot simply extract the surplus by tailoring the contractual terms of employment to each employee's actual abilities. For example, consider an employer that wishes to promote a small proportion of its entry-level employees based on the employees' observed productivity during a long probationary period: If the employees exhibit different expected productivities, then the strongest workers might be able to shirk without fear that they will be passed over for promotion. Because the employees' exact capabilities are unknown to the employer, simply requiring employee-specific minimum output would not allow the employer to extract all of the expected gains from trade. Instead, the employer might be able to do better by subsidizing some of the weaker applicants in this competition. Faced with this subsidized competition, the employees with the highest expected productivity may work harder.

${ }^{145}$ Schotter \& Weigelt, supra note 127. For groups with a severe disadvantage, affirmative action significantly increased effort and firm profits. Without the affirmative action, the disadvantaged parties tended to supply no effort, since their chance of promotion was so small. Id.

${ }^{146}$ One intriguing study of stock market "events" shows that when the Labor Department announced awards for companies that had exemplary affirmative action programs, the companies' stock prices increased. Peter Wright, Stephen P. Ferris, Janine S. Hiller \& Mark Kroll, Competitiveness Through Management of Diversity: Effects on Stock Price Valuation, 38 ACAD. MGMT. J. 272 (1995).

${ }^{147}$ We can think of few examples where private employers explicitly subsidize weaker applicants to spur competition, but "secondsourcing"-where a firm profitably subsidizes a higher cost second-source to enhance its bargaining power with the primary input supplier-may be analogous. See Ayres \& Braithwaite, supra note 139, at 134.

${ }^{148}$ City of Richmond v. J.A. Croson Co., 109 S. Ct. 706 (1989) (requiring that city affirmative action plan satisfy a compelling governmental interest and be narrowly tailored to remedy the past effects of discrimination).

${ }^{149}$ Adarand Constr. v. Pena, 115 S. Ct. 2097 (1995) (holding that all governmental racial classifications must withstand strict judicial scrutiny).

${ }^{150} I d$. at 2117 . Gender-based subsidies may be more likely to pass constitutional muster because they need not satisfy strict scrutiny. Mississippi Univ. for Women v. Hogan, 458 U.S. 718, 724 (1982) (subjecting gender-based discrimination to intermediate scrutiny). Even under the relevant "heightened scrutiny," however, it may be difficult for the government to justify revenue enhancement as a substantial government purpose.
} 
unlikely to qualify as a "compelling government purpose" for disparate racial treatment. ${ }^{151}$ Even if increasing government revenue were a constitutionally permissible goal, the means of achieving this goal would not be "narrowly tailored," because there is a strong possibility the government could find a racially neutral means of substantially achieving the same goal. Specifically, if the FCC had simply subsidized small firms, ${ }^{152}$ similar revenue-enhancing effects might have been achieved.

Whether a small-firm subsidy would create more or less revenue than a race/gender subsidy depends in part on the government's ability to identify a stable, nonracial class of "weak" bidders. While many critics of affirmative action have complained that sham corporations have falsely qualified for minority status, ${ }^{153}$ the problem of "sham" corporations might be even more intractable if preferred status were determined simply by a corporation's revenue or financial structure. Strong bidders might be able to redefine their corporate structure to qualify for small business subsidies. Thus, while it is possible that racial and/or gender classifications are the best means to enhance bidding competition, we think it clear that the current Supreme Court would not accept revenue enhancement by itself as a sufficient justification for affirmative action set-asides.

\section{Did the FCC's rules enhance minority or female control of the airwaves?}

To underscore our agnosticism about whether the FCC's affirmative action was consistent with the Constitution's equal protection requirement, we digress for a moment to consider whether the FCC's designated bidder regulations enhanced minority or female control of the airwaves. The FCC designed the designated bidder regulations to avoid two problems: (1) unjust enrichment and (2) sham designated bidders. The unjust enrichment problem was created by bad publicity generated when previous lottery winners quickly resold their licenses for huge profits. ${ }^{154}$ The FCC responded by promulgating detailed unjust enrichment rules aimed at stopping unjust minority enrichment. These rules restricted designated bidders' ability to resell or lease licenses in the short term to non-designated bidders, and required repayment both of the 40 percent bidding credit and the installment subsidy if the license were resold in the long term. ${ }^{155}$ These rules should stop unscrupulous designated bidders from capitalizing on the affirmative action subsidies. Indeed, because the 40 percent bidding credit did not mean that designated bidders actually paid 40 percent less than non-designated bidders for comparable licenses, the pay back rules may discourage even legitimate resale. ${ }^{156}$

The FCC also attempted to deter corporations from trying to get designated status by using minority or female entrepreneurs as fronts, without allowing them any actual control over the corporation. The FCC therefore required that women or minorities own a majority of the voting stock and at least 25 percent of the total (voting and nonvoting) equity. ${ }^{157}$

The greatest weakness of the FCC's approach was its failure to limit the amount or terms of designated bidder leverage. While nonvoting stock could represent no more than 75 percent of total equity, designated bidders were allowed to borrow unlimited amounts from their passive equity holders. In fact, female or minority entrepreneurs did not have to pay in any capital in return for their majority control; some designated bidders financed 100 percent of their auction payments with debt and capital contributions from nonvoting shareholders. Moreover,

\footnotetext{
${ }^{151}$ The Court would likely require the government to show that there was no equally effective race-neutral means to achieve the same result. See Adarand, 115 S. Ct. at 2118. In Adarand, two justices even wrote that there could be no compelling government purpose for racebased subsidies. Id. at 2118-19 (Scalia, J. and Thomas, J., concurring separately).

${ }^{152}$ Although in the regional narrowband auction the FCC subsidized firms with annual gross revenues of less than $\$ 40$ million $\mathrm{m}$ the last two years, the subsidies were not as significant as those given to designated bidders. Small firms received no bidding credit, but they were able to pay in installments at the 10-year treasury note rate. The installment payments applied to all licenses. See Order on Reconsideration, supra note 49, at 5306-07.

${ }^{153}$ See, e.g., Mark I. Pinsky, FCC Takes Trinity TV Station: Religious Broadcaster Illegally Used Minority Status, U.S. Says, SUNSENTINEL, Nov. 16, 1995, at 1D, available in LEXIS, News Library, Curnws File (" "[T]he findings establish that TBN and Crouch created a sham corporation to take advantage of the minority preference' policies of the FCC.”).

${ }^{154}$ See, e.g., Edmund L. Andrews, Airwave Auction Bill Advances, N.Y. TimEs, May 12, 1993, at D1, D13; Edmund L. Andrews, Senate Plan to Sell Radio Frequencies, N.Y. TIMES, May 28, 1992, at D1, D9.

${ }^{155}$ Implementation of Section 309(j) of the Communications Act-Competitive Bidding, 9 F.C.C.R. 2348, 2394-95 (1994) (Second Report and Order, PP Docket No. 93-253) [hereinafter Second Report \& Order].

${ }^{156}$ The extensive crossover bidding and the designated bidder purchase of a non-set-aside license suggest that the effective bidding credit was $0 \%$ (not including the installment benefit).. Thus, making the designated bidders pay back the full $40 \%$ actually penalizes resellers. Although designated bidders presumably take this illiquidity into account when valuing designated licenses, requiring overpayment of the bidding credit will tend to increase the inefficient holding of designated licenses.

${ }^{157}$ Third Memorandum \& Order, supra note 49, at 212. In addition, if the designated bidder control group owned less than half of the total equity, then no single non-designated investor could own more than $25 \%$ of the total equity or more than $15 \%$ of the voting stock. Id.

The FCC's rules, however, did not prohibit designated bidders from adopting supermajority voting requirements that might undermine the effective control of the control group. For example, while a woman owned $85 \%$ of Benbow P.C.S. Ventures, Inc., her dominant ownership share was insufficient to make many major corporate decisions, because any such decision required approval from $86 \%$ of the voting shares. Long Form Application of Benbow P.C.S. Ventures, Inc., FCC Form 401, Exh. VI at 1 (Nov. 23, 1994).
} 
while designated bidders were required to file a "long-form" application to qualify for designated status, they never had to disclose the amount or terms of debt financing.

The lack of leverage regulation created a strong likelihood of extreme separation of ownership from control. The FCC did not limit the amount of free cash flow passive financiers could take from the corporation. The FCC's regulations thus permitted a leaky bucket-where many of the benefits of affirmative action ultimately flowed to people who were not members of the disadvantaged group. FCC apologists might respond that capital markets are sufficiently competitive to protect designated entrepreneurs and that the goal of the program is to let designated entrepreneurs control part of the telecommunications spectrum. However, the complete lack of leverage regulation threatens to undermine the more limited goal of giving women and minority entrepreneurs effective control of the designated firms.

Passive financiers in these ventures must have been sorely tempted to control the bidding strategies when millions of dollars of their own money were at stake. The FCC regulations failed to specify the amount of control that passive debtholders and nonvoting stockholders were allowed to exert. Quite possibly, these so-called passive financiers might have made round-by-round bidding decisions, with the ultimate threat of withholding financing should the controlling shareholders act otherwise. In other instances, exerting this type of influence has exposed passive debtholders to various types of control liability. ${ }^{158}$

While we cannot assess who controlled the bidding strategies of the prevailing designated bidders in the regional auction, an analysis of their long-form applications for designated status indicates extreme forms of leverage. For example, Lisa-Gaye Shearing disclosed that its passive partner financed 100 percent of the more than $\$ 3$ million spent for auction prepayments. ${ }^{159}$ Moreover, some of the designated bidders seemed to cede control of the bidding process to their white male financiers. ${ }^{160}$ For example, the female controlling shareholder of Benbow seemed detached during important parts of the bidding, and one of us observed her reading a novel for several rounds while her white male team decided how to bid. ${ }^{161}$

Because the entrepreneurs who own the designated firms did not face the same threats of ouster by proxy contest or merger as those who run typical corporations, it strains the imagination to think that nonvoting shareholders and debtholders would extend virtually all of the firm's working capital without retaining substantial influence over its most important decisions. Race- and gender-conscious subsidies must do more than merely enhance government revenues to pass constitutional muster, and we remain agnostic about whether the FCC subsidies achieved these additional requirements.

\section{Affirmative action costs the government less than is commonly assumed.}

Notwithstanding the fact that a revenue-enhancing effect is not constitutionally sufficient to justify affirmative action, our finding that affirmative action can enhance government revenue has normative relevance. The cost of affirmative action is significant to determining its wisdom as a matter of public policy. Affirmative action may appear more attractive if it costs the government very little to redress past discrimination. Even if race- and gender-based subsidies further a compelling government purpose, the amount of affirmative action must turn, at least in part, on the cost of the subsidy. ${ }^{162}$

From this perspective, it is not crucial that the FCC's affirmative action subsidy actually increased government revenue-it is only important that the subsidy cost the government less than is commonly assumed. The government cost of affirmative action is exaggerated if one considers only the shortfall on contracts that go to minorities. A more accurate view takes account of the ways in which subsidized minority bidders drive traditional players to surrender more of the gains of trade on the contracts they win. The naive analysis wrongly assumes as a benchmark that unsubsidized bidders would have bid as aggressively in the absence of competition from preferred bidders. The naive benchmark also wrongly assumes that minority bidders only compete with

\footnotetext{
${ }^{158}$ See, e.g., A. Gay Jenson Farms Co. v. Cargill, Inc., 309 N.W.2d 285, 294 (Minn. 1981) (holding lender vicariously liable to other creditors because its financial and managerial control over the principal created an agency relationship); see also RESTATEMENT (SECOND) OF AGENCY $§ 14(\mathrm{o}) \mathrm{cmt}$. a (1957) (security holder may be considered principal of debtor where security holder takes over management of debtor); Daniel R. Fischel, The Economics of Lender Liability, 99 YALE L.J. 131 (1989).

${ }^{159}$ Long Form Application of Page Call, Inc., FCC Form 401 Exh. IV at 5, 7 (Nov. 23, 1994) (on file with the Stanford Law Review). Benbow similarly disclosed: "Westlink teas advanced funds to Benbow to make the necessary down payments to the Commission." Long Form Application of Benbow, P.C.S. Ventures, Inc., supra note 157, at 2.

${ }^{160}$ Shearing's long form states that she "had an oral agreement [with her passive partner, Adelphia] that they would consult with each other on bidding strategies during the auction and, to the extent Lisa-Gaye Shearing chose not to be present at the auction, she would direct what bids to place in what markets and an Adelphia employee would act as her agent in placing those bids." Long Form Application of Page Call, supra note 159 , at 5 .

${ }^{161}$ While controlling shareholders might rationally delegate many corporate decisions, it seems odd that the controlling shareholder would delegate how the corporation invests the vast majority of its capital. Benbow's observed behavior is all the more disheartening if one of the goals of affirmative action is to create role models for future disadvantaged entrepreneurs.

${ }^{162}$ Assessing the cost of affirmative action will also turn on a variety of other factors, including the cost of excluding white males and the amount of social inefficiency.
} 
unsubsidized bidders-therefore that competition among minority bidders does not compete away any of the subsidy. But in the narrowband auction, designated competition was sufficient to do just this-competing away virtually all of the 40 percent bidding credit. What naively seems like a huge giveaway ended up costing the government nothing. As our examination of the FCC auction reveals, subsidizing discrete classes of bidders can increase both inter-and intragroup competition, invalidating both of the naive assumptions.

While we have shown that the affirmative action subsidies increased revenues in comparison to an auction without any bidder subsidies, some critics might argue that we have not chosen the appropriate benchmark and in particular that we should use for comparison an auction with the most effective race-and gender-neutral subsidies. We emphasized above that small business subsidies might have been able to generate more government revenue than the affirmative action subsidies did. ${ }^{163}$ Yet even if giving small business subsidies could have extracted higher bids from the dominant bidders, our central finding would still hold: Affirmative action subsidies cost much less than we would have estimated if we merely multiplied the eleven licenses that designated bidders acquired by the effective 50 percent (or in one case 16 percent) subsidy. ${ }^{164}$

This naive method would estimate that affirmative action cost the government $\$ 125.6$ million. A small business subsidy may have succeeded in extracting even more from the established bidders, and in comparison with this benchmark, affirmative action may still have cost the government some revenue. But this shortfall in revenue would only be a fraction of the naive cost estimate.

Even if the race and gender subsidies had not increased government revenues, the take-home lesson of this article is that the fiscal cost of affirmative action may be much less than the facial expense of a 50-cents-on-thedollar subsidy. In a sense, the legal significance of our finding is captured by the simple idea that "demand curves slope downward"-meaning the discovery that affirmative action has a lower price should, on the margin, induce society to demand more of it.

\section{B. Private Affirmative Action May Deserve Higher Scrutiny}

Our discovery that affirmative action subsidies can enhance bidding competition does not unambiguously militate for an increase in all types of affirmative action. The theoretical possibility that employers may adopt race-conscious hiring or promotion standards solely to make money suggests that private affirmative action may deserve higher scrutiny than currently given in Title VII litigation.

A bed-rock principle of Title VII is that there is no profitability defense for disparate treatment on the basis of race or gender. ${ }^{165}$ Particularly with regard to disparate racial treatment, the statute explicitly excludes racial classifications as a possible "bona fide occupational qualification." 166 equal protection jurisprudence, which requires the symmetrical treatment of laws favoring and disfavoring racial minorities ${ }^{167}$ Title VII distinguishes between race-conscious employment standards that favor minorities and those that disfavor them. Thus, even though "there is no BFOQ for race' when disfavoring minorities, the Supreme Court has said that race-conscious disparate treatment (in the form of an employer's voluntary affirmative action program that favors minorities) does not violate Title VII if it is intended to "eliminate a manifest racial imbalance" and does not unduly burden or absolutely bar the advancement of white employees. ${ }^{168}$

Our enhanced-competition theory suggests, however, that employers might engage in affirmative action solely to extract more surplus from their white and/ or male employees. While the Supreme Court has not yet treated race-conscious employment practices that favor and disfavor minorities symmetrically, we suspect that the Court would require symmetric application if it thought that a private employer adopted a voluntary affirmative action program solely to increase profits. The Supreme Court may therefore require employers to prove more than a statistical imbalance - that is, to make some showing that they are motivated by more compelling factors than making money. ${ }^{169}$

Yet the need for heightened scrutiny turns in large part on how often private employers would likely implement voluntary affirmative action solely to make money. In our previous analysis, we sketched how racial and gender preference might enhance a firm's profits, but concluded that in practice employers would seldom

\footnotetext{
${ }^{163}$ See note 152 supra and accompanying text.

${ }^{164}$ See text accompanying note 62 supra.

${ }^{165}$ See City of L.A. Dep’t of Water \& Power v. Manhart, 435 U.S. 702, 716-17 (1978) (noting that "Title VII [does not] contain ... a cost-justification defense comparable to the affirmative defense available in a price discrimination suit.").

16642 U.S.C. $§ 2000 \mathrm{e}-2(\mathrm{e})(1)(1994)$.

${ }^{167}$ See, e.g., 42 U.S.C. \$ 1981 (1994).

168 Johnson v. Transportation Agency, Santa Clara County, 480 U.S. 616, 630 (1987) (citing United Steelworkers of America v. Weber, 443 U.S. 193, 208 (1979)).

${ }^{169}$ Our interim conclusion that Title VII should prohibit affirmative action programs adopted solely to increase an employer's profits, however, has broader application: Namely, the more conventional "diversity" justification for affirmative action-improving decisionmaking by increasing the diversity of decisionmakers-would also violate Tide VII unless the employer could offer a sufficient nonprofit based motive.
} 
have the information necessary to calculate the appropriate subsidy with any confidence. ${ }^{170}$ Accordingly, heightening the employer's standard of justification because of the possibility of enhanced employee competition seems unwarranted. ${ }^{171}$

\section{CONCLUSION}

In undertaking this study, we set out to estimate how much the bidding subsidies cost our government. Our first intuition was that allowing firms controlled by women and/or minorities to pay just 50 percent of their winning bids would lower the government's auction revenue. Only after analyzing the bidding data through the lens of game theory did it become clear that the FCC's affirmative action increased narrowband prices by forcing nonpreferred firms to bid more aggressively. In a simultaneous auction, the last bidders to drop out determine final prices — and in the regional narrowband auction the subsidized designated bidders dropped out last, but only after they drove up final prices by 12 percent or $\$ 45$ million.

Our results demonstrate how law-and-economics can illuminate otherwise counterintuitive behavior. The game-theoretic explanation does not come naturally to those unschooled in strategic thinking. Civil rights advocates have implicitly conceded that affirmative action subsidies burden the public fisc- they argue instead that the social benefits of remedying past discrimination or of promoting diversity justify the cost of the government subsidies. Showing that the subsidies cost much less than previously thought—or indeed that the subsidies may reduce the federal deficit—makes it easier for affirmative action programs to pass cost-benefit analysis.

Opponents of affirmative action might contend that the effect on the public fisc should not be dispositive. But for those who believe that there is an appropriate role for affirmative action in remedying past discrimination or in furthering diversity, then the results of this article will help illuminate the size of the public subsidy.

The United States has a long history of giving away the radio spectrum: ${ }^{172}$ From 1927 until 1982, radio spectrum licenses were assigned by a process known as "comparative hearings" in which the FCC evaluated competing requests for broadcast licenses. The licenses were simply given away-once applicants had paid their lawyers significant sums to construct arguments explaining why they would best serve the nebulous "public interest." By 1982, the volume of new cellular telephone licenses began to overwhelm the FCC's ability to conduct comparative hearings, so Congress authorized the agency to assign the licenses by lotteries, again without charge. Hundreds of thousands of firms applied for the giveaway-many only with the desire to resell their lottery winnings for a profit. ${ }^{173}$

Congress' decision to auction licenses went a long way toward ending these blatant giveaways-but even in an auction, entitlements can be sold on the cheap if there are not enough bidders. The recent FCC auctions created just this risk. Had large telecommunications companies reaped windfalls by purchasing licenses at prices substantially below their valuations, the auctions would have continued the trend of giving away the spectrum. Though requiring disadvantaged firms to pay just 50 percent of their winning bids struck many commentators as an unjustifiable giveaway, ${ }^{174}$ we have shown that besides promoting diverse ownership of the broadcast spectrum, the FCC's affirmative action actually prevented an even larger corporate gratuity.

\footnotetext{
${ }^{170}$ See text accompanying notes 143-147 supra.

${ }^{171}$ While this article has focused on the impact of affirmative action at the regional narrowband auction, installment payments and bidding credits for designated bidders have had large effects in other FCC spectrum auctions. For example, in the C-block broadband PCS auction for designated bidders, prices as of February 25, 1996, were nearly double the prices in the early MTA broadband PCS auction, where two bands ( $\mathrm{A}$ and $\mathrm{B}$ ) were sold to non-designated bidders. The average final price in the early broadband auction was $\$ 15.54$ per pop; whereas the average net price in the C-block auction was $\$ 27.70$ per pop for an identical $30 \mathrm{MHz}$ license. See http://www.fcc.gov. Competition in the first auction was weak compared to that of the set-aside auction, in which small businesses were given a $25 \%$ bidding credit and installment payments similar to those in the regional narrowband auction. The evidence is strong that the earlier auction ended at prices well below full value because of the lack of competition in many markets. See Cramton, supra note 2, at 31. Judging from the intense competition in the C-block auction, the FCC may have raised substantially more revenues in the broadband auctions if the auctions for the A, B. and C blocks were combined into one auction and C-block bidders were given installment payments in the A and B blocks. In any event, it is clear that the bidding credits and installment payments did not cost the taxpayers a penny. The broadband results illustrate an important disadvantage of using set-asides. Namely, set-asides do not permit the crossover bidding between designated and non-designated licenses. As a result revenues may suffer in one market or the other.

172 This history is detailed in MILGROM, supra note 46, at 2, 12-13.

${ }^{173}$ Milgrom gives the example of a sham telephone company, i.e. one formed solely for the purpose of filing lottery applications, that won the right to supply cellular services to Cape Cod and promptly resold its license to Southwestern Bell Telephone Company for $\$ 41$ million. MILGROM, supra note 46, at 13.

${ }^{174}$ See, e.g., Rauch, supra note 8, at 9, 12 (discussing "discriminating for the sake of discriminating" in interactive video and paging licenses).
} 


\section{APPENDIX}

Table 5 shows on a license-by-license basis how we calculated the information in Table 4 . The full names of the relevant bidders appear in Table 2, with the exception of the non-designated bidder, KDM Messaging Co. (McCaw), which is a wholly owned subsidiary of McCaw Cellular, now owned by AT\&T. The information contained under the heading "Last Non-Designated Bidder Excess Demand" reports the last time an unsuccessful non-designated bidder entered a bid on a particular license. For example, for the Midwest Region/Block 1 license, McCaw placed the last unsuccessful non-designated bid of $\$ 12.6$ million in round 6 . The next column, "Response to Final Bids By Non-Designated Bidders Who Ultimately Dropped Out," simply reports how the ultimate winners responded to this excess non-designated demand. For example, in response to McCaw's Midwest/Block I bid, PageMart bid \$16 million. We assume that, without the crossover designated bidding, prices for the licenses would have risen to this level, because there was demonstrated excess non-designated demand at lower prices. While it would be tempting to use this response as the benchmark estimate as the price for which each license would sell, this method ignores the fact that 50/12 licenses within the same region are close to perfect substitutes (for any bidder not seeking a national aggregation). To calculate a more conservative estimate of the effect of crossover bidding, we assumed a bidder expressing demand of $\$ 12$ million on a Block 3 regional license would have been willing to bid as much for the similar regional license on Blocks 4 and 5 . Accordingly, we calculated, for each region, the maximum response on three 50/12 licenses (to the final bids by non-designated bidders that ultimately dropped out). We used this higher figure as our benchmark for expected revenue in the absence of affirmative action. For example, we assume that Westlink would have been willing to replicate its bid of $\$ 8.941$ million on the West Block 5 license on all of the West 50/12 licenses, and used the response of $\$ 9.4$ million as the relevant benchmark for each of the three licenses. The bottom of the table aggregates the increase in revenue by block-the overall increase of $\$ 44.9$ million. 


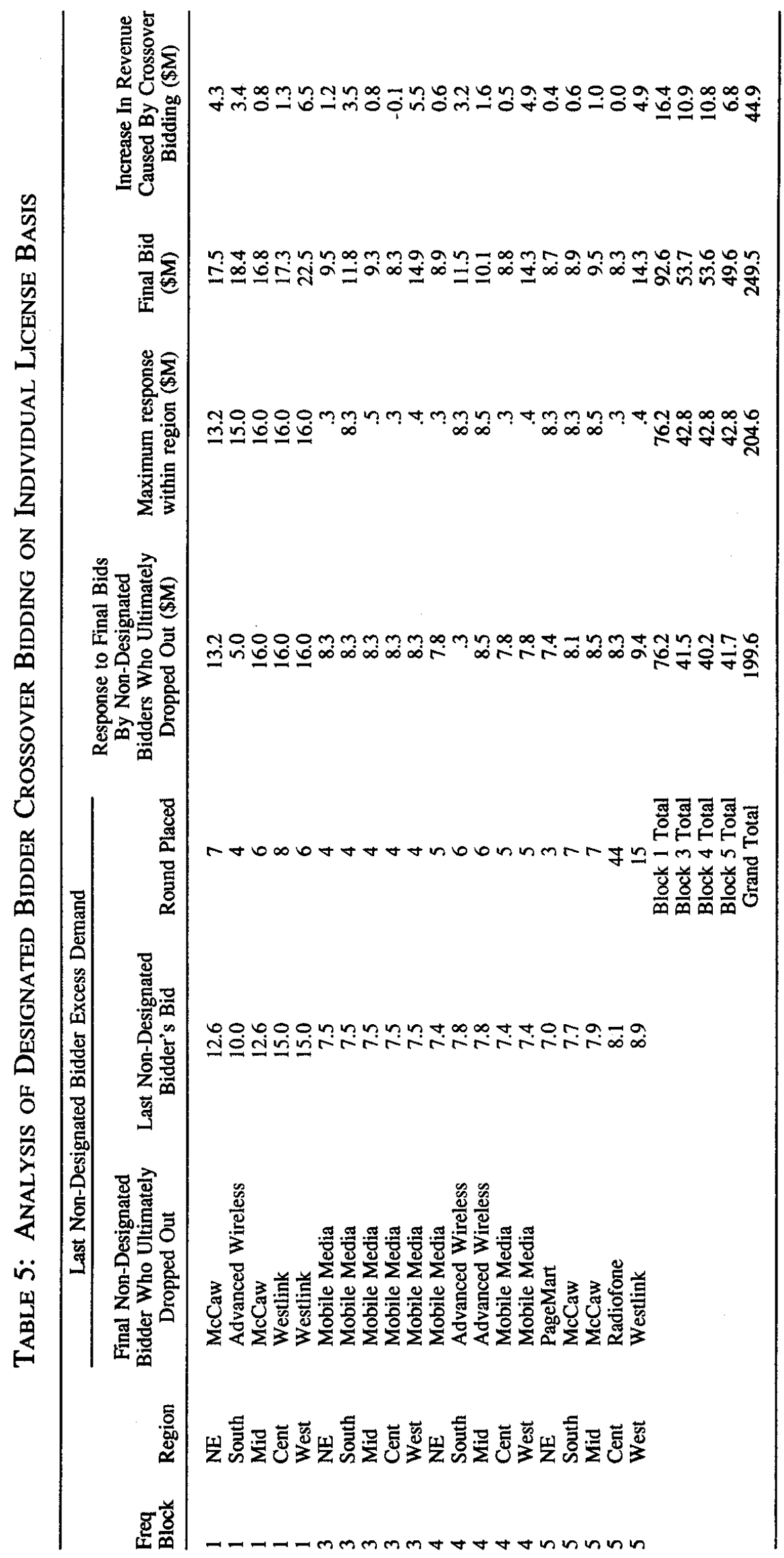

